\title{
Modeling and Analysis of Hormone and Mitogenic Signal Integration in Prostate Cancer
}

Katharine V. Rogers, Joseph A. Wayman, Ryan Tasseff, Caitlin Gee, Matthew

P. DeLisa, and Jeffrey D. Varner*

School of Chemical and Biomolecular Engineering

Cornell University, Ithaca NY 14853

Running Title: Modeling signal transduction in prostate cancer

To be submitted: Scientific reports

${ }^{*}$ Corresponding author current address:

Jeffrey D. Varner,

Professor, School of Chemical and Biomolecular Engineering,

244 Olin Hall, Cornell University, Ithaca NY, 14853

Email: jdvarner@purdue.edu

Phone: (607) 255 - 4258 


\section{Abstract}

Prostate cancer is the most common cancer in men and the second leading cause of cancer-related death in the United States. Androgens, such as testosterone, are required for androgen dependent prostate cancer (ADPC) growth. Androgen ablation in combination with radiation or chemotherapy remains the primary non-surgical treatment for ADPC. However, androgen ablation typically fails to permanently arrest cancer progression, often resulting in castration resistant prostate cancer (CRPC). In this study, we analyzed a population of mathematical models that described the integration of androgen and mitogenic signaling in androgen dependent and independent prostate cancer. An ensemble of model parameters was estimated from 43 studies of signaling in androgen dependent and resistant $\mathrm{LNCaP}$ cell lines. The model population was then validated by comparing simulations with an additional 33 data sets from LNCaP cell lines and clinical trials. Analysis of the model population suggested that simultaneously targeting the PI3K and MAPK pathways in addition to anti-androgen therapies could be an effective treatment for CRPC. We tested this hypothesis in both ADPC LNCaP cell lines and LNCaP derived CRPC C4-2 cells using three inhibitors: the androgen receptor inhibitor MDV3100 (enzalutamide), the Raf kinase inhibitor sorafenib, and the PI3K inhibitor LY294002. Consistent with model predictions, cell viability decreased at $72 \mathrm{hrs}$ in the dual and triple inhibition cases in both the LNCaP and C4-2 cell lines, compared to treatment with any single inhibitor. Taken together, this study suggested that crosstalk between the androgen and mitogenic signaling axes led to robustness of CRPC to any single inhibitor. Model analysis predicted potentially efficacious target combinations which were confirmed by experimental studies in multiple cell lines, thereby illustrating the potentially important role that mathematical modeling can play in cancer.

Keywords: Prostate cancer, signal transduction, mathematical modeling 


\section{Introduction}

Prostate cancer $(\mathrm{PCa})$ is the most commonly diagnosed cancer and the second leading cause of cancer-related death in men in the United States [78]. Initially, PCa cells depend upon the activation of cytosolic androgen receptors (AR) by androgen hormones, such as testosterone, for survival and growth. Thus, androgen ablation in combination with radiation or chemotherapy remains the primary non-surgical treatment for androgen dependent prostate cancer (ADPC) [42]. However, androgen ablation typically fails to permanently arrest cancer progression as malfunctioning cells eventually lose androgen sensitivity and proliferate without hormone. The loss of androgen sensitivity results in castration resistant prostate cancer (CRPC), a phenotype closely linked with metastasis and reduced survival [34]. Currently, there are six approved treatments demonstrating a survival advantage in patients with metastatic CRPC, each target different aspects of the disease [72]. The taxane family members docetaxel and cabazitaxel interact with microtubule stability [19, 86], while abiraterone [72] and enzalutamide [74] interfere with androgen signaling by blocking androgen formation and nuclear translocation, respectively. Other treatments are not specific to PCa. For example, sipuleucel-T, a first generation cancer vaccine [44], or radium-223, an alpha emitter which targets bone metastasis [64], are both approved to treat CRPC. Unfortunately, regardless of the therapeutic approach, the survival advantage of these treatments is typically only a few months. Thus, understanding the molecular basis of the loss of androgen sensitivity in CRPC is an important step for the development of effective therapeutic strategies.

Androgen-induced proliferation and survival depends upon coordinated signal transduction and gene expression events. AR is a member of the nuclear hormone receptor superfamily, which includes other important receptors such as progesterone receptor (PR) and estrogen receptor (ER) [2]. Nuclear hormone receptors act as ligand dependent transcription factors interacting with specific DNA sequences on target genes as either 
monomers, heterodimers, or homodimers; AR, PR, and ER act as homodimers. For AR, these specific DNA sequences are called androgen response elements (ARE) [58]. In the absence of androgen, AR is predominately found in the cytoplasm bound to chaperones such as heat shock protein (HSP) [70]. Androgens, either testosterone or testosterone metabolites such as $5 \alpha$-dihydrotestosterone (DHT), interact with cytosolic AR, promoting the dissociation of AR from HSP [69] and its subsequent dimerization, phosphorylation and translocation to the nucleus [4]. Activated nuclear AR drives a gene expression program broadly referred to as androgen action, that promotes both proliferation and survival. In addition to many genes including itself, activated nuclear AR promotes the expression and secretion of prostate specific antigen (PSA), arguably the best known PCa biomarker [22], although its prognostic ability is controversial [3, 40,61].

Androgen dependent $(\mathrm{AD})$ prostate cells become castration resistant $(\mathrm{CR})$ through several possible mechanisms, including constitutively amplified AR expression, or altered AR sensitivity to testosterone or other non-androgenic molecules [22]. In this study, we focused on a third possible mechanism, the aberrant activation of AR by kinase signaling cascades, sometimes called the outlaw pathway. Outlaw activation can be driven by overor constitutively activated receptor tyrosine kinases (RTKs), a common pathology in many cancer types including PCa [16, 79]. RTKs stimulate downstream kinases, including the AKT and mitogen-activated protein kinase (MAPK) pathways, which promote AR phosphorylation and dimerization in the absence of androgen [16, 96]. Interestingly, among the few genes activated AR represses is cellular prostatic acid phosphatase (cPAcP), itself a key negative regulatory of RTK activation [90]. Thus, in CRPC the androgen program is initiated without the corresponding extracellular hormone cue, potentially from crosstalk between growth factor and hormone receptor pathways. In turn, aberrant androgen action downregulates negative regulators of its own activation thereby forming a reinforcing positive feedback loop. 
In this study, we analyzed a population of mathematical models that described the integration of androgen and mitogenic signaling in androgen dependent and independent prostate cancer. The model architecture was a significant advance over our previous prostate signaling model [87]. We added the regulated expression of ten additional proteins, including the cell cycle restriction point protein cyclin D, and included the regulation of AR action by cyclin D1a and the E2F transcription factor. We estimated model parameters using multiobjective optimization in combination with dynamic and steady-state data sets generated in $A D$, intermediate and CR PCa cell lines. We identified a population of models which described both $A D$ and $C R$ data sets using a single model structure. An ensemble of model parameters was estimated from 43 studies of signaling in androgen dependent and resistant LNCaP cell lines. The model population was then validated by comparing simulations with an additional 33 data sets from LNCaP cell lines and clinical trials. Analysis of the model population suggested that simultaneously targeting the PI3K and MAPK pathways in addition to anti-androgen therapies could be an effective treatment for CRPC. We tested this hypothesis in both ADPC LNCaP cell lines and LNCaP derived CRPC C4-2 cells using three inhibitors: the androgen receptor inhibitor MDV3100 (enzalutamide), the Raf kinase inhibitor sorafenib, and the PI3K inhibitor LY294002. Consistent with model predictions, cell viability decreased at $72 \mathrm{hrs}$ in the dual and triple inhibition cases in both the LNCaP and C4-2 cell lines, compared to treatment with any single inhibitor. Taken together, this study suggested that crosstalk between the androgen and mitogenic signaling axes led to robustness of CRPC to any single inhibitor. Model analysis predicted efficacious target combinations which were confirmed by experimental studies in multiple cell lines, thereby illustrating the potentially important role that mathematical modeling can play in cancer. 


\section{Results}

Estimating a population of prostate signaling models. We modeled the integration of growth factor and hormone signaling pathways in AD and CR LNCaP cells (Fig. 1). The signaling architecture was curated from over 80 primary literature sources in combination with biological databases. We modeled both protein-protein interactions, and gene expression reactions involved in hormone and mitogenic signaling (Materials and Methods). The model equations were formulated as a system of ordinary differential equations (ODEs), where biochemical reaction rates were modeled using mass action kinetics. We estimated an ensemble of possible parameter sets using the Pareto Optimal Ensemble Techniques (POETs) algorithm [81]. POETs uses a combination of simulated annealing and local optimization techniques coupled with Pareto optimality-based ranking to simultaneously optimize multiple objective functions. Starting from an initial best fit set, we estimated the unknown model parameters using 43 in vitro data sets taken from six AD, intermediate and CR LNCaP cell lines (Table T1). Each of the training data sets was a separate objective in the multiobjective optimization calculation. The training data were steady-state or dynamic immunoblots from which we extracted relative species abundance using their optical density profiles. POETs generated well over a million possible parameter sets, from which we selected the top $\mathrm{N}=5000$ sets for further analysis. The coefficient of variation (CV) of the parameter ensemble spanned $0.59-5.8$, with $33 \%$ of the parameters having a $\mathrm{CV}$ of less than one (Fig. S1). As a control, we also performed simulations for $R=100$ random parameter sets to compare against the parameters estimated by POETs.

The population of signaling models recapitulated training data in both $A D$ and $C R$ cell lines with two experimentally mandated parameter changes (Fig. 2 and Fig. 3). Data from the LNCaP clones C-33 (dependent), C-51 (intermediate), and C-81 (resistant) [41, 43, 53] along with the CR LNCaP cell lines LNCaP-Rf [62], LNCaP-Al [11] and 
LNAI [26] were used for model identification. To simulate the effective difference between LNCaP cell lines, the parameter controlling the maximum rate of PAcP gene expression was scaled by 0.1 and 0.5 , respectively, for the C-81 and C- 51 cell-lines compared to C-33. This modification was based upon steady-state PAcP data from the three LNCaP clones [48]. Similarly, the expression of p16INK4 was adjusted in accordance with the study of Lu et al. [57]. These two parameters were the only adjustable parameter differences between $A D$ and $C R$ cells. To simulate an increased mTOR activation in the presence of a DHT stimulus, we added a first order activation term for mTOR activation with a DHT stimulus. Androgens increase the expression of proteins involved in cellular metabolism, leading to increased mTOR activation [94]. Conservatively, the model ensemble described approximately $85 \%$ of the training objectives (Fig. $2 \mathrm{~A}$ ), while only $20 \%$ of the training objectives were captured with the random parameter control (Fig. 2B). Thus, POETs identified a population of models that described the training data significantly better than a random parameter control.

The population of models captured the crosstalk between RTK activation and androgen action (Fig. 3). The model described DHT-induced PSA expression (PSA is an ARinducible gene) in both C-33 (Fig. 3A) and C-81 (Fig. 3B) cells. Simulations with the HER2 inhibitor AG879 also recapitulated decreased PSA expression in C-81 cells in the absence of androgen, highlighting the crosstalk between RTK and androgen action (Fig. 3C); AR action also decreased the PAcP mRNA message, presumably leading to increased HER2 activity (Fig. 3D). The model also recapitulated the integration of androgen action with AR expression, G1/S cell cycle protein expression and AKT phosphorylation. For example, the model captured AR-induced AR expression following a DHT stimulus (Fig. 3H). Conversely, the transcription factor E2F inhibited AR transcription in LNCaP cells (Fig. 3I). Other cell cycle proteins were also integrated with androgen action. For example, the cyclin D1 abundance increased in CR compared to AD cells in the absence of androgen 
(Fig. 3E), while DHT induced p21Cip1 expression in C-33 cells (Fig. 3F). The level of phosphorylated AKT also increased in higher passage number cells (Fig. 3G). Thus, the estimated model population recapitulated signaling and crosstalk behavior in both $A D$ and CR LNCaP training data, above a random control. However, given the complexity of the model, it was unclear if the model ensemble could predict unseen data. To address this question, we fixed the model parameters and ran simulations of experimental data not used for model training.

Validation simulations revealed missing network structure. The model was validated against 29 in vitro and four in vivo clinical studies (Table T2). For 15 of the 29 cases, the ensemble was qualitatively consistent with the experimental data (Fig. 2C). However, for the random parameter control, only 7 of the 29 cases were satisfied (Fig. 2D). We correctly predicted positive feedback between HER2 auto-activation and androgen action (Fig. 4A and Fig. 4B). We also captured the dose-dependence of AR abundance on DHT (Fig. 4C). In addition to the cell line studies, we simulated the outcome of enzalutamide, lapatinib, and sorafenib clinical trials in AD and CRPC patients. The trial end points were the reduction in PSA expression relative to an untreated baseline. Enzalutamide acts on AR by inhibiting its nuclear translocation, DNA binding, and coactivator recruitment [74]. In the enzalutamide trial, $54 \%$ of the patients that received the drug showed a PSA decline of $\geq 50 \%$ while $25 \%$ showed a decline $\geq 90 \%$. We simulated enzalutamide exposure by reducing the rate constants governing activated AR binding to nuclear importer, cyclin E, and CDK6 to $1 \%$ of their initial values. Consistent with the trial, $62 \%$ of ensemble members showed $a \geq 50 \%$ decline in PSA abundance, while $14 \%$ showed $a \geq 90 \%$ decline (Fig. 4G). Next, we simulated the response of our model population to lapatinib, an inhibitor of epidermal growth factor receptor (EGFR) and HER2 tyrosine kinase activity [55]. Two lapatinib drug trials were considered: one in which patients had CRPC and one in which patients had biochemically relapsed $\operatorname{ADPC}[55,93]$. In the CRPC lapatinib trial, 
9.5\% of the enrolled patients had a PSA response $\geq 47 \%$ [93], while our model ensemble showed 26\% PSA response rate. Of the 35 patients enrolled in the ADPC lapatinib study, no PSA decreases was observed [55]; the model ensemble showed less than a 10\% PSA response rate (data not shown). However, while no response to lapatinib was seen in ADPC clinical trials, in vitro AD LNCaP experiments showed decreased PSA expression in response to lapatinib, most notably with the addition of DHT [56]. Lastly, we simulated the response of CRPC patients to sorafenib, a kinase inhibitor with activity against Raf, vascular endothelial growth factor receptor (VEGFR), platelet-derived growth factor receptor (PDGFR), c-kit and c-Ret [17]. We considered only the effects of sorafenib on Raf, as the others were not included in the model. None of the 22 patients in the sorafenib study showed a PSA decline of $>50 \%$. However, our simulations showed that approximately $55 \%$ of the ensemble members had a PSA decline of $\geq 50 \%$ (Fig. $4 \mathrm{I}$ ). Taken together, the model ensemble predicted approximately $55 \%$ of the validation cases overall, but $75 \%$ of the clinical test cases. The failed clinical cases, and many of the failed training and validation cases, involved RTK activation, and in particular epidermal growth factor (EGF) signaling, suggesting the model was missing key biology.

Training and validation failures suggested the original signaling architecture was missing critical components related to EGF signaling. Several of the failed training and validation simulations involved the response of the network to EGF stimulation. For example, Chen et al. showed that HER2 phosphorylation increased within five minutes following EGF stimulation of LNCaP-AI cells [11]. However, we predicted no connection between HER2 phosphorylation and EGF stimulation on this short timescale (Fig. 4E). Interestingly, we initially neglected the heterodimerization of HER2 with other ErbB family members to simplify the model. Chen et al. suggested that HER2-EGFR heterodimerization was an important factor in EGF-driven activation of HER2 [11]. We tested this hypothesis by developing a new model that included HER2 and EGFR heterodimerization (all else 
held the same). We set the rate constants governing the assembly of HER2/EGFR heterodimers equal to EGFR homodimer assembly; all other parameters were unchanged. We felt this was a reasonable first approximation, as the affinity of HER2/EGFR heterodimerization and EGRF homodimerization is thought to be similar [38]. With the inclusion of HER2-EGFR heterodimerization, we qualitatively described EGF-induced HER2 activation, and more generally improved our training peformance for experiments that involved an EGF stimulus, e.g., cyclin D mRNA and protein abundance following an EGF stimulus in C-33 cells (Fig. 2A and C, white pixels and Fig. S2). This structural update to the model improved the training percentage to approximately $90 \%$, and also highlighted an advantage of the ensemble modeling approach. Next, we analyzed the ensemble of models using both local and global techniques to estimate which parameters and processes were controlling system performance for AD and CR cells.

Sensitivity analysis identified differentially important network features. Sensitivity analysis identified important signaling components in AD versus CR cells (Fig. 5). We calculated first order steady-state sensitivity coefficients under different stimuli for 500 parameter sets randomly selected from the ensemble. The sensitivity profile was similar for $A D$ versus $C R$ cells in the presence of DHT (Fig. $5 B$ ). The top $2 \%$ of sensitive species belonged to either the MAPK or PI3K pathways. In particular, activated Ras, Raf, phosphorylated MEK, PIP3 localized AKT, phosphorylated AKT, and PI3K were sensitive in both $\mathrm{AD}$ and CR cells. PAcP and p16INK4 along with E2F, cyclin E, and DHT-activated AR were more sensitive in AD cells. On the other hand, HER2 activation of PI3K, and AKT inhibition of Raf were more sensitive in CR cells. Taken together, in the presence of $\mathrm{DHT}, \mathrm{AD}$ and $\mathrm{CR}$ cells shared a similar sensitivity profile with only a few differences. This suggested androgen had a strong influence on network performance even for CR cells. Next, we analyzed the ensemble of models in the absence of androgen.

The importance of signaling components varied with androgen dependence in the ab- 
sence of DHT (Fig. 5A). There were 108 sensitivity shifts that were greater than one standard deviation above the mean shift. In CR cells, HER2 activation of ERK and PI3K was more sensitive, as was AR activation through the MAPK pathway. In general, the MAPK pathway was more sensitive, and SPAcP more robust in CR cells. This was expected, as outlaw pathway activity is elevated in castration resistant cells. On the other hand, infrastructure pathways encoding transcription and translation were more sensitive in AD cells. PSA and cyclin D1b (mRNA and mRNA complexes) were the only species involved in translation that were more robust in AD cells. This would suggest that the targeting of transcription or translation mechanisms in CR cells may be less effective than in $A D$ cells. The transcription factor, E2F was more fragile in AD cells, while the transcription factors ETS and AP1 were more robust. The model included AP1 suppression of AR transcriptional activity (more sensitive in CR) [73], as well as inhibition of transcription of the AR gene by E2F (more sensitive in AD) [18]. Species in the PI3K pathway that were more fragile in $A D$ cells included Rheb and TOR complexes. Interestingly, these species were included as the last step in the PI3K pathway prior to translation, with the phosphorylation of $4 \mathrm{E}-\mathrm{BP} 1$ by TOR being considered the beginning of translation in this model. This again indicates that in the absence of DHT general translation is more fragile in AD cells.

Next we considered the importance of signaling components in the presence and absence of androgen for the same cell type. There were a total of 119 significant shifts between an androgen and a non-androgen environment in AD and CR cells (Fig. 5C and Fig. S3). Unsurprisingly, AR activation through DHT binding, with and without coactivators, in a DHT environment was more sensitive, as was AR inhibition of PAcP transcription (repressed by AR in the model). Species further upstream, such as HER2 activation of the MAPK and PI3K/AKT pathways, were also more sensitive in a DHT environment. This is most likely the result of the positive feedback between androgen action and HER2 activation in the model. Cell cycle species that were more fragile in the presence of DHT 
included complexes involving p21Cip1 and CDC25A. In a non-androgen environment, basal transcription and translation were more sensitive. Other sensitive species in the absence of DHT included Rb, E2F, Sam68, cyclin D1a complexes, MAPK phosphatases, and Rheb/TOR complexes. Notably, the value of the species sensitivity ranking shifts for basal transcription and translation in an androgen versus a non-androgen environment were higher in $A D$ vs $C R$ cells (Fig. 5C and Fig. S3). This again may indicate that in an androgen free environment in an $\mathrm{AD}$ cell, targeting of general translation and transcription may be beneficial, but may be less effective in a CR cell.

Lastly, we considered the sensitivity of CR cells in the presence of the AR inhibitor enzalutamide with and without DHT. The top $2 \%$ of sensitive species with and without enzalutamide were conserved in the presence of DHT (Fig. 5D). Species which were more sensitive with enzalutamide and DHT included cytosolic AR, cPAcP, and p21Cip1. As expected, nuclear AR was more robust in the presence of enzalutamide. Enzalutamide prevents translocation of $A R$ to the nucleus causing levels of nuclear $A R$ to decrease and cytosolic AR to increase. In CR cells, enzalutamide had no effect on the sensitivity of PI3K/AKT or MAPK species, many of which were included in the top $2 \%$ of sensitive species. Next, we looked at the effect of enzalutamide on CR cells without DHT (Fig. S3). Dimerized HER2, ERK, and PAcP were more sensitive in a non-androgen environment with enzalutamide. Species which were more robust in the non-androgen environment included, AR activated by DHT, AKT, p70, and AR bound to HSP. Taken together, the sensitivity results suggested that instead of inhibiting the AR pathway alone (enzalutamide), a combination approach targeting the PI3K or MAPK pathways in addition to AR could be more effective in treating CR cells. However, first-order sensitivity coefficients measure the result of infinitesimal changes to model parameters. Thus, they may not faithfully reflect the outcome of a finite perturbation to the network. To address this shortcoming, next we simulated the response of $A D$ and $C R$ cells to knockouts or amplification of network 
components.

Robustness analysis confirmed the need for dual inhibition. Robustness analysis was conducted to quantify the effects of amplifying or removing key model components in $A D$ and $C R$ cells. Gene expression parameters were altered by a factor of $10,0.5$, and 0 for knock-in, knock-down, or knock-out perturbations, respectively. We calculated the effect of these perturbations on the expression or activation of different protein markers, such as PSA, AR, cyclin D, activated p70 and phosphorylated AKT. In particular, we calculated the effect of knock-out perturbation in CR cells for seven cases: (1) Raf knockout, (2) PI3K knock-out, (3) AR knock-out, (4) Raf and PI3K knock-outs, (5) Raf and AR knock-outs, (6) PI3K and AR knock-outs, and (7) Raf, PI3K and AR knock-outs. Over the 500 models sampled, the greatest decrease in PSA expression occurred for cases involving AR knock-outs (Fig. 6A). On the other hand, the greatest decrease in activated p70 abundance occurred for the PI3K/AR and the triple Raf/PI3K/AR knock-out cases (Fig. 6B). The median and mean response for cyclin D expression was near zero for all knock-out cases (Fig.6C). However, there was significant variance over the population of models (both increased and decreased expression) in response to the perturbations. As expected, PI3K activity was required for AKT phosphorylation, while other knockouts had little influence on AKT phosphorylation (Fig. 6D). However, as was true with cyclin D, there was a subpopulation of models with increased AKT phosphorylation for cases involving RAF and RAF/AR knock-outs. These results support our case for a combination treatment approach, with PSA, activated p70, and AKT phosphorylation all decreasing in the PI3K/AR knock-out case as well as the RAF/PI3K/AR knock-out case.

Next we looked at single gene expression perturbations to understand the variance over the population of models. A knock-out of Raf, MEK or ERK showed an average overall increase in cyclin D levels in CR cells (Fig. S4). This was unexpected and we saw a similar increase in cyclin D due to the knock-in of Raf, MEK or ERK. We found that 
individual models showed different response to a Raf knock-out, in both cyclin D and PSA abundance. We saw three distinct regions: (1) increased PSA expression, (2) increased cyclin D expression, and (3) decrease in both PSA and cyclin D expression. Of the 500 models, 126 models had increased PSA expression, and 62 models had increased cyclin D expression due to the knock-out of Raf (Fig. 7). We explored the flux vectors of the outlying parameter sets to understand the mechanistic effect of Raf knock-out on PSA and cyclin D. Outlying parameter sets in region 1 displayed high activation of PI3K through HER2 signaling as well as high association of AP1 with AR. AP1 is known to bind and suppress AR transcriptional activity in LNCaP cells [73]. Knocking out Raf lowered AP1 levels and, therefore, freed AR for increased transcription of PSA. Models in region 2 also had high activation of PI3K through HER2, as well as higher association of E2F with $\mathrm{Rb}$ and cyclin D1a with AR. Cyclin D levels in region 2 increased due to an increase in E2F levels caused by the Raf knock-out. Models in region 3 had high association of mTOR. Interestingly, the drug sorafenib, a multi-kinase inhibitor that has activity against Raf, showed no measurable PSA decline in prostate cancer patients in clinical trials [17]. The robustness analysis showed that network perturbation can result in unexpected responses due to heterogeneity in signal transduction and gene expression processes.

Experimental studies confirmed the effectiveness of dual and triple inhibition. Sensitivity and robustness analysis, conducted over a subpopulation of prostate signaling models, suggested that simultaneously targeting the PI3K and MAPK pathways in addition to anti-androgen therapies could be an effective treatment for CRPC. To test this hypothesis, we measured the response of the well characterized ADPC cell line LNCaP as well a LNCaP derived CRPC cell line C4-2 to inhibitor and inhibitor combinations (Fig. 8). Three inhibitors were used: the AR inhibitor MDV3100 (enzalutamide), the Raf kinase inhibitor sorafenib, and the PI3K inhibitor LY294002. Inhibitor concentrations were chosen to be approximtaly in the mid-range of the dose-response curves for each cell line after 24 
hrs of exposure (Fig. 8C). In both cell lines, inhibition of either the AR or MAPK pathways promoted activation of the PI3K pathway, as seen by the increase in phosphorylated AKT (S473) (Fig. 8A). The addition of the PI3K inhibitor, LY294002, alone or in combination diminished PI3K activity (Fig. 8A). Interestingly, the inhibition of PI3K alone, increased AR expression in both $\mathrm{LNCaP}$ and $\mathrm{C} 4-2$ cell lines (Fig. 8A). Since AR transcriptionally regulates its own expression, this suggested PI3K inhibition increased AR activity. The ribosomal protein pS6 was completely inhibited only in the presence of the PI3K inhibitor LY294002. The abundance of cleaved PARP (c-PARP), an indicator for apoptosis, was highest in the triple inhibition case for both LNCaP and C4-2 cell lines, however c-PARP also increased in the dual inhibition of RAF and PI3K in both cell lines and in the dual inhibition of PI3K and AR in C4-2 cells (Fig. 8A). We further characterized cellular viability using the MTT assay. Cell viability decreased at $72 \mathrm{hrs}$ in the dual and triple inhibition cases for both LNCaP and C4-2 cell lines (Fig. 8B). However, MDV3100 (10 $\mu \mathrm{M})$ alone had only a modest effect on cell viability versus control (DMSO). 


\section{Discussion}

In this study, we analyzed a population of mathematical models that described androgen and mitogenic signaling in androgen dependent and independent prostate cancer. An ensemble of model parameters was estimated using 43 steady-state and dynamic data sets taken from androgen dependent, intermediate and independent LNCaP cell lines using multiobjective optimization. The model ensemble captured $85 \%$ of the training data, compared with $20 \%$ for the random parameter control. We tested the predictive power of the model ensemble by comparing simulations with 33 data sets (including four in vivo drug studies) not used for training. The model ensemble correctly predicted approximately $55 \%$ of the validation cases overall, but $75 \%$ of the clinical cases. During ensemble generation we identified potentially important missing biology. Addition of one such case, EGF-induced HER2/EGFR heterodimerization, improved both training and validation performance with no additional parameter fitting. Analysis of the model population suggested that simultaneously targeting the PI3K and MAPK pathways in addition to anti-androgen therapies could be an effective treatment for CRPC. We tested this hypothesis in both ADPC LNCaP cell lines and LNCaP derived CRPC C4-2 cells using three inhibitors: the androgen receptor inhibitor MDV3100 (enzalutamide), the Raf kinase inhibitor sorafenib, and the PI3K inhibitor LY294002. Consistent with model predictions, cell viability decreased at $72 \mathrm{hrs}$ in the dual and triple inhibition cases in both the LNCaP and C4-2 cell lines, compared to treatment with any single inhibitor alone. Thus, crosstalk between the androgen and mitogenic signaling axes led to the robustness of CRPC to any single inhibitor. However, model analysis predicted efficacious target combinations which were confirmed by experimental studies in multiple cell lines, thereby illustrating the potentially important role that mathematical modeling can play in cancer.

Three of the validation cases missed by the model involved the effect of EGF on AR and AR-activated gene expression. However, the inhibition of AR activation by EGF re- 
mains an open question, with many groups debating the biology involved, particularly the role of the PI3K/AKT pathway. Multiple groups have shown decreased expression of AR and androgen-regulated PSA due to EGF stimulus in some prostate cell lines [8, 15]. Simulations of the model ensemble showed either the opposite trend or no effect due to EGF stimulus. This response may be dependent on androgen status. Lin et al. found that in low passage number LNCaP cells (C-33), AKT negatively regulated AR by destabilizing it and promoting ubiquitylation. On the other hand, in high passage number LNCaP cells (C-81), AKT levels were high which contributed to AR stability and less degradation [51]. Cai et al. found that AR protein levels in CR cells were not affected by EGF [8]. Others though have found that PSA expression, even in C-81 cells, is decreased by EGF [32]. In other prostate cell lines, EGF has been shown to increase AR transactivation $[28,68]$. Much of the debated biology involves the effect of AKT activation on AR. For example, Wen et al. showed that HER2 induced AKT activation and LNCaP cell growth in the presence and absence of androgen [92]. While another study showed AKT phosphorylation of AR at S213 and S790 suppressed AR transactivation and AR-mediated apoptosis of LNCaP [52]. The MAPK pathway, which is downstream of EGFR, may also enhance AR responses to low levels of androgen [30,91]. Thus, due to the discrepancies in the literature, additional experiments should be performed before revising the network connectivity to the model.

Analysis of the population of PCa models identified key signaling components and processes in $A D$ and $C R$ cells. There was little difference between sensitive and robust processes in $A D$ versus $C R$ cells in the presence of androgen. The MAPK and PI3K pathways were consistently ranked in the top $2 \%$ of sensitive species in the presence of androgen, while cell cycle species, such as cyclin D-CDK4/6 complexes bound to cell cycle inhibitors (p27Kip1, p21Cip1, p16INK4), were consistently robust. However, this profile changed considerably in the absence of androgen. The activation of PI3K and 
ERK by HER2 dimerization and autophosphorylation, and ERK-mediated AR activation was significantly more important in $C R$ versus $A D$ cells. On the other hand, although ARregulated gene expression was equally sensitive between the cell types, transcriptional and translational processes were more robust in CR versus AD cells. This evidence supports the current theory that CR cells will still respond to androgen, and that AR can be activated in the absence of androgens by MAPK activation [22]. Thus, AR is still an active therapeutic target against CRPC [45]. Interestingly, the androgen inhibitor enzalutamide had no effect on the top $2 \%$ of sensitive species. Species in the PI3K/AKT and MAPK pathways in the presence of enzalutamide were still highly sensitive. The application of enzalutamide increased sensitivity of AR species found outside of the nucleus as well as PAcP species. Informed by our sensitivity results, we performed robustness analysis to determine the effect of combination treatments on key model proteins. Robustness analysis indicated diverse effects of Raf knock-out on PSA and cyclin D concentrations. Clinical studies of sorafenib, a multi-kinase inhibitor that has activity against Raf, showed increase PSA levels in patients [17]. Our results indicate that cell-to cell heterogeneity in gene expression can play a significant role in determining cell response. Thus, combination therapies need to be considered even in the case of a Raf knock-out.

Analysis of the population of PCa models suggested inhibition of either the PI3K or the MAPK pathways in combination with AR inhibition was a possible therapeutic strategy to treat CRPC. Carver et al. looked at dual inhibition of AR and PI3K signaling in LNCaP cells and in a PTEN-deficient murine prostate cancer model [64]. They found that a combination of the PI3K inhibitor, BEZ235, and the AR inhibitor, MDV3100 (enzalutamide) dramatically reduced the total cell number and increased c-PARP in the dual inhibition case. These findings lead to the hypothesis that AKT inhibition increased AR activity through increased HER3. On the other hand, AR inhibition increased AKT activity due to the down regulation of PHLPP, a protein phosphatase that regulates AKT. Dual and triple 
knock-out simulations of PI3K, AR (and RAF) showed only a slight additive effect on the cell cycle protein cyclin D. Thus, the combined decrease in cell population observed by Carver et al. was likely due to cell death and not cell-cycle arrest. The model also showed decreased cell cycle proteins in the PI3K knock-out as well as in the PI3K and AR dual knock-out case in some ensemble members. This was consistent with the decreased cell count in the PI3K inhibition case, which is not dependent on cell death as c-PARP levels were low. The decrease in cell cycle proteins in the model was due to decreased translation, including reduced levels of elF4E and activated $40 \mathrm{~S}$ ribosomal subunits. Decreased p70 (S6) activation due to PI3K inhibition was shown in both the model and by Carver et al. Lastly, our experimental results confirmed the Carver et al. study; dual inhibition of the AR and PI3K pathways decreased cell viability more than each of the individual inhibitors alone. We explored the addition of a third inhibitor, the Raf inhibitor sorafenib, and added an additional CR cell line, C4-2. There was no significant decrease in cell viability between the three dual inhibitor cases and the triple inhibition case at 74 hours. Thus, dual inhibition (PI3K/AR, AR/MAPK, or PI3K/MAPK) may be a sufficient treatment for CRPC.

The PCa signaling architecture was assembled after extensive literature review and hand curation of the biochemical interactions. However, there are a number of areas where model connectivity could be refined, e.g., the regulation of AR phosphorylation. We assumed a single canonical activating AR phosphorylation site (S515), with ERK being the major kinase and PP2A or PP1 being the major phosphatases responsible for regulating this site. MAPK activation following EGF treatment increases AR transcription and cell growth, partially through AR phosphorylation on MAPK consensus site S515 [68]. However, there are at least 13 phosphorylation sites identified on AR, with phosphorylation at six of these being androgen induced [25]. Moreover, other kinases such as AKT, protein kinase $C(P K C)$ family members, as well as Src-family kinases can all phosphorylate AR in prostate cells $[30,68]$. For example, AKT activation leads to AR phosphorylation at both 
S213 and S791, however, the role of these sites remains unclear [51, 52, 85, 92]. AKT effects on AR may also be passage number dependent, with AKT repressing AR transcription in low passage number cells and enhancing transcription in higher passage cells [51]. Androgen independent phosphorylation of AR by Src family kinases (not currently in the model) at $\mathrm{Y} 534[30]$ or by protein kinase $\mathrm{C}$ (PKC) family members at the consensus site S578 could also be important for understanding the regulation of AR activity. A second area we will revisit is the gene expression program associated with androgen action, and particularly the role of AR coregulators. Currently, we included only two AR coactivators, cyclin E and CDK6 $[50,95]$ and three corepressors AP1, Cdc25A, and cyclin D1a in the model $[13,67,73]$. However, there are at least 169 proteins classified as potential AR coregulators $[35,36]$ with many of these being differentially expressed in malignant cells. For example, the expression of steroid receptor coactivator-1 (Src-1) and transcriptional intermediary factor 2 (Tif-2), both members of the steroid receptor coactivator family, are elevated in prostate cancer $[28,29]$. Src- 1 is phosphorylated by MAPK and interacts directly with $A R$ to enhance AR-mediated transcription [35]. Another class of potentially important AR coregulators are the cell cycle proteins Cdc25 and Rb. Unlike Cdc25A, Cdc25B (not in the model) can act as an AR coactivator leading to enhanced AR transcription activity [63]. The $\mathrm{Rb}$ protein, in addition to being a key cell cycle regulator, has been shown to be an AR coactivator in an androgen-independent manner in DU145 cells [97]. However, there is some uncertainty about the role of Rb as Sharma et al. showed that $R b$ decreased $A R$ activation in multiple prostate cancer cell lines and xenografts [76]. Forkhead proteins have also been shown to activate as well as repress AR function. In prostate cancer, AKT suppresses AFX/Forkhead proteins, which diminishes expression of AFX target genes, such as p27Kip1 [6, 27, 59, 83]. Lastly, undoubtedly there are several other signaling axes important in $\mathrm{PCa}$, such as cytokine or insulin- and insulin-like growth factor signaling $[9,37,75,84]$. Understanding the pathways associated with these 
bioRxiv preprint doi: https://doi.org/10.1101/058552; this version posted June 13, 2016. The copyright holder for this preprint (which was not certified by peer review) is the author/funder, who has granted bioRxiv a license to display the preprint in perpetuity. It is made available under aCC-BY 4.0 International license.

signals and how they relate to the current model, may give us a more complete picture of androgen sensitivity and progression of prostate cancer. 


\section{Materials and Methods}

Prostate model signaling architecture. We modeled the transcription, translation and post-translational modifications of key components of the PCa signaling architecture. The model, which consisted of 780 protein, lipid or mRNA species interconnected by 1674 interactions, was a significant extension to our previous model [87] in several important areas. First, we included well-mixed nuclear, cytosolic, membrane and extracellular compartments (including transfer terms between compartments). Next, we expanded the description of growth factor receptor signaling, considering both homo- and heterodimer formation between ErbB family members and the role of cellular and secreted prostatic acid phosphatase (cPAcP and SPAcP, respectively). Both forms of PAcP were included because cPAcP downregulates HER2 activity, while sPAcP promotes modest HER2 activation [90]. Third, we expanded the description of the G1/S transition of the cell cycle (restriction point). The previous model used the abundance of cyclin $\mathrm{D}$ as a proliferation marker, but did not include other proteins or interactions potentially important to the restriction point. Toward this shortcoming, we included cyclin E expression (and its role as a coregulator of androgen receptor expression), enhanced the description of cyclin D expression and the alternative splicing of cyclin D mRNA (including the role of the splice variants in androgen action), included the Rb/E2F pathway as well as E2F inhibition of androgen receptor expression [18], and the cyclin-dependent kinases cyclin-dependent kinase 4 (CDK4) and cyclin-dependent kinase 6 (CDK6). We also included key inhibitors of the restriction point including cyclin-dependent kinase inhibitor 1 (p21Cip1), cyclin-dependent kinase inhibitor 1B (p27Kip1), and cyclin-dependent kinase inhibitor 2A (p16INK4) [77]. Fourth, we enhanced the description of growth factor induced translation initiation. One of the key findings of the previous model was that growth factor induced translation initiation was globally sensitive (important in both androgen dependent and independent conditions). However, the description of this important subsystem was simplified in the 
previous model. Here, we expanded this subsystem, using connectivity similar to previous study of Lequieu et al. [49], and re-examined the importance of key components of this axis, such as mammalian target of rapamycin (mTOR), phosphatidylinositide 3-kinase (PI3K) and AKT. Lastly, we significantly expanded the description of the role of androgen receptor. The previous model assumed constant AR expression, consistent with studies in androgen dependent and independent LNCaP sublines [48]. However, other prostate cancer cell lines vary in their AR expression [80]. Thus, to capture androgen signaling in a variety of prostate cancer cells, we included the transcriptional regulation governing androgen receptor expression, updated our description of the regulation of androgen receptor activity and androgen action (gene expression program driven by activated androgen receptor). At the expression level, we included AR auto-regulation in combination with the co-activators cyclin E and CDK6 [50, 95]. We also assumed androgen receptor could be activated through androgen binding or a ligand-independent, MAPK-driven mechanism referred to as the outlaw pathway $[22,96]$. We assumed a single canonical activating AR phosphorylation site (S515), with phosphorylated extracellular-signal-regulated kinase 1/2 (ppERK1/2) being the major kinase and protein phosphatase 2 (PP2A) or phosphoprotein phosphatase 1 (PP1) being the major phosphatases responsible for regulating this site. Finally, we modeled androgen receptor induced gene expression, including prostate specific antigen (PSA), cPAcP and p21Cip1.

Formulation and solution of the model equations. The prostate model was formulated as a coupled set of non-linear ordinary differential equations (ODEs):

$$
\frac{d \mathbf{x}}{d t}=\mathbf{S} \cdot \mathbf{r}(\mathbf{x}, \mathbf{k}) \quad \mathbf{x}\left(t_{o}\right)=\mathbf{x}_{o}
$$

The quantity $\mathrm{x}$ denotes the vector describing the abundance of protein, mRNA, and other species in the model $(780 \times 1)$. The stoichiometric matrix $\mathbf{S}$ encodes the signaling architec- 
ture considered in the model $(780 \times 1674)$. Each row of $\mathbf{S}$ describes a signaling component while each column describes a particular interaction. The $(i, j)$ element of $\mathbf{S}$, denoted by $\sigma_{i j}$, describes how species $i$ is involved with interaction $j$. If $\sigma_{i j}>0$, species $i$ is produced by interaction $j$. Conversely, If $\sigma_{i j}<0$, then species $i$ is consumed in interaction $j$. Lastly, if $\sigma_{i j}=0$, then species $i$ is not involved in interaction $j$. The term $\mathbf{r}(\mathbf{x}, \mathbf{k})$ denotes the vector of interactions rates $(1674 \times 1)$. Gene expression and translation processes as well as all biochemical transformations were decomposed into simple elementary steps, where all reversible interactions were split into two irreversible steps (supplemental materials). We modeled each network interaction using elementary rate laws where all reversible interactions were split into two irreversible steps. Thus, the rate expression for interaction $q$ was given by:

$$
r_{q}\left(\mathbf{x}, k_{q}\right)=k_{q} \prod_{j \in\left\{\mathbf{R}_{q}\right\}} x_{j}^{-\sigma_{j q}}
$$

The set $\left\{\mathbf{R}_{q}\right\}$ denotes reactants for reaction $q$, while $\sigma_{j q}$ denotes the stoichiometric coefficient (element of the matrix S) governing species $j$ in reaction $q$. The quantity $k_{q}$ denotes the rate constant (unknown) governing reaction $q$. Model equations were generated in the C-programming language using the UNIVERSAL code generator, starting from an text-based input file (available in supplemental materials). UNIVERSAL, an open source Objective-C/Java code generator, is freely available as a Google Code project (http://code.google.com/p/universal-code-generator/). Model equations were solved using the CVODE solver in the SUNDIALS library [39] on an Apple workstation (Apple, Cupertino, CA; OS X v10.6.8).

We ran the model to steady-state before calculating the response to DHT or growth factor inputs. The steady-state was estimated numerically by repeatedly solving the model 
equations and estimating the difference between subsequent time points:

$$
\|\mathbf{x}(t+\Delta t)-\mathbf{x}(t)\|_{2} \leq \gamma
$$

The quantities $\mathrm{x}(t)$ and $\mathrm{x}(t+\Delta t)$ denote the simulated abundance vector at time $t$ and $t+\Delta t$, respectively. The $L_{2}$ vector-norm was used as the distance metric, where $\Delta t=100$ hr of simulated time and $\gamma=0.001$ for all simulations.

We estimated an ensemble of model parameter sets using the Pareto Optimal Ensemble Techniques (POETs) multiobjective optimization routine $[49,81,82]$. POETs minimized the residual between model simulations and 43 separate training objectives taken from protein and mRNA signaling data generated in androgen dependent, intermediate and independent LNCaP cell lines (Table T1). From these training objectives, POETs generated $>10^{6}$ candidate parameter vectors from which we selected $\mathrm{N}=5000$ Pareto rank-zero vectors for further analysis. The set-to-set correlation between selected sets was approximately 0.60 , suggesting only modest similarity between ensemble members. Approximately $33 \%$, or 560 of the 1674 parameters had a coefficient of variation (CV) of less than 1.0, where the CV ranged from 0.59 to 5.8 over the ensemble $(N=5000)$. Details of the parameter estimation problem and POETs are given in the supplemental materials.

Sensitivity and robustness analysis. Steady-state sensitivity coefficients were calculated for $\mathrm{N}=500$ parameter sets selected from the ensemble by solving the augmented kinetic-sensitivity equations [20]:

$$
\left[\begin{array}{c}
\mathbf{S} \cdot \mathbf{r}(\mathbf{x}, \mathbf{k}) \\
\mathbf{A}\left(t_{s}\right) \mathbf{s}_{j}+\mathbf{b}_{j}\left(t_{s}\right)
\end{array}\right]=\left(\begin{array}{l}
\mathbf{0} \\
\mathbf{0}
\end{array}\right) \quad j=1,2, \ldots, \mathcal{P}
$$


where

$$
s_{i j}\left(t_{s}\right)=\left.\frac{\partial x_{i}}{\partial k_{j}}\right|_{t_{s}}
$$

for each parameter set. Steady-state was calculated as described previously. The quantity $j$ denotes the parameter index, A denotes the Jacobian matrix, and $\mathcal{P}$ denotes the number of parameters in the model. The vector $\mathbf{b}_{j}$ denotes the $j$ th column of the matrix of first-derivatives of the mass balances with respect to the parameters. Steady-state sensitivity coefficients were used because of the computational burden associated with sampling several hundred parameters sets for each of the 1674 parameters. The steadystate sensitivity coefficients $\mathcal{N}_{i j} \equiv s_{i j}$ were organized into an array for each parameter set in the ensemble:

$$
\mathcal{N}^{(\epsilon)}=\left(\begin{array}{cccccc}
\mathcal{N}_{11}^{(\epsilon)} & \mathcal{N}_{12}^{(\epsilon)} & \ldots & \mathcal{N}_{1 j}^{(\epsilon)} & \ldots & \mathcal{N}_{1 P}^{(\epsilon)} \\
\mathcal{N}_{21}^{(\epsilon)} & \mathcal{N}_{22}^{(\epsilon)} & \ldots & \mathcal{N}_{2 j}^{(\epsilon)} & \ldots & \mathcal{N}_{2 P}^{(\epsilon)} \\
\vdots & \vdots & & \vdots & & \vdots \\
\mathcal{N}_{M 1}^{(\epsilon)} & \mathcal{N}_{M 2}^{(\epsilon)} & \ldots & \mathcal{N}_{M j}^{(\epsilon)} & \ldots & \mathcal{N}_{M P}^{(\epsilon)}
\end{array}\right) \quad \epsilon=1,2, \ldots, N_{\epsilon}
$$

where $\epsilon$ denotes the index of the ensemble member, $P$ denotes the number of parameters, $N_{\epsilon}$ denotes the number of parameter sets sampled $(\mathrm{N}=500)$ and $M$ denotes the number of model species. To estimate the relative fragility or robustness of species and reactions in the network, we decomposed $\mathcal{N}^{(\epsilon)}$ using Singular Value Decomposition (SVD):

$$
\mathcal{N}^{(\epsilon)}=\mathbf{U}^{(\epsilon)} \Sigma^{(\epsilon)} \mathbf{V}^{T,(\epsilon)}
$$

Coefficients of the left singular vectors corresponding to largest $\theta \leq 15$ singular values of $\mathcal{N}^{(\epsilon)}$ were rank-ordered to estimate important species combinations, while coefficients of the right singular vectors were used to rank important reaction combinations. Only coefficients with magnitude greater than a threshold $(\delta=0.001)$ were considered. The fraction 
of the $\theta$ vectors in which a reaction or species index occurred was used to quantify its importance (sensitivity ranking). We compared the sensitivity ranking between different conditions to understand how control in the network shifted in different cellular environments.

Robustness coefficients were calculated as shown previously [88]. Robustness coefficients denoted by $\alpha\left(i, j, t_{o}, t_{f}\right)$ are defined as:

$$
\alpha\left(i, j, t_{o}, t_{f}\right)=\left(\int_{t_{o}}^{t_{f}} x_{i}(t) d t\right)^{-1}\left(\int_{t_{o}}^{t_{f}} x_{i}^{(j)}(t) d t\right)
$$

Robustness coefficients quantify the response of a marker to a structural or operational perturbation to the network architecture. Here $t_{o}$ and $t_{f}$ denote the initial and final simulation time respectively, while $i$ and $j$ denote the indices for the marker and the perturbation respectively. A value of $\alpha\left(i, j, t_{o}, t_{f}\right)>1$, indicates increased marker abundance, while $\alpha\left(i, j, t_{o}, t_{f}\right)<1$ indicates decreased marker abundance following perturbation $j$. If $\alpha\left(i, j, t_{o}, t_{f}\right) \sim 1$ the $j$ th perturbation does not influence the abundance of marker $i$. Robustness coefficients were calculated (starting from steady-state) from $t_{o}=0 \mathrm{hr}$ to $t_{f}=72 \mathrm{hr}$ following the addition of $10 \mathrm{nM}$ DHT at $t_{o}$. For scaled log fold change we used the following equation:

$$
\alpha_{\text {scaled }}(i, j)= \begin{cases}\frac{\log _{10}(\alpha(i, j))}{\max \log _{10}(\alpha(i))}, & \text { if } \log _{10}(\alpha(i, j)) \geq 0 \\ -\frac{\log _{10}(\alpha(i, j))}{\min \log _{10}(\alpha(i))}, & \text { if } \log _{10}(\alpha(i, j))<0\end{cases}
$$

A value of $\alpha_{\text {scaled }}(i, j)>0$, indicates increased marker abundance, while $\alpha_{\text {scaled }}(i, j)<0$ indicates decreased marker abundance following perturbation $j$. If $\alpha_{\text {scaled }}(i, j) \sim 0$ the $j$ th perturbation does not influence the abundance of marker $i$. A value of $\alpha_{\text {scaled }}(i, j)=1$, indicates max increase of marker abundance, while $\alpha_{\text {scaled }}(i, j)=-1$ indicates the max decrease of marker abundance. Robustness coefficients were calculated for the same $\mathrm{N}$ 
$584=500$ models selected for sensitivity analysis.

Cell culture and treatments Androgen dependent LNCaP prostate cancer cells were a gift from Dr. Brian Kirby (Cornell University), and the castration resistant C4-2 prostate cancer cell line was purchased from MD Anderson Cancer Center, University of Texas. Cell lines were maintained in RPMI 1640 media (Life Technologies, Inc., Grand Island, NY) with $10 \%$ fetal calf serum (FBS; Hyclone) and 1x antibiotic/antimycotic (Sigma, St. Louis, MO) in a $5 \% \mathrm{CO}_{2}$ humidified atmosphere at $37^{\circ} \mathrm{C}$. The AR inhibitor MDV3100 (enzalutamide) and the Raf inhibitor sorafenib were purchased from SantaCruz Biotechnology (Santa Cruz, CA). The PI3K inhibitor LY294002 was purchased from Cell Signaling Technologies (Danvers, MA, USA). All stock solutions were diluted in DMSO and stored at $-20^{\circ} \mathrm{C}$ (Sigma, St. Louis, MO). Stock solution concentrations for western blotting experiments were $10 \mathrm{mM}$ Sorafenib, $50 \mathrm{mM}$ LY294002, and $10 \mathrm{mM}$ MDV3100. For the cell viability assays, stock solution concentrations were 0.5 mM Sorafenib, 4 mM LY294002, and $1 \mathrm{mM}$ MDV3100.

Protein extraction and western blot analysis LNCaP and C4-2 cells were seeded in $60 \mathrm{~mm}$ dishes at a density of $4 \times 10^{5}$. After 96 and $72 \mathrm{hrs}$, for LNCaP and C4-2 cells respectively, the media was replaced with fresh media and drug treatments were added. After 24 hours, cells were washed twice in PBS buffer, scraped in $250 \mu \mathrm{L}$ ice-cold lysis buffer (Pierce, Rockford, IL) supplemented with protease and phosphatase inhibitors (Sigma, St. Louis, MO), and lysed for $30 \mathrm{~min}$ on ice. Lysates were centrifuged at 13,000 rpm for 30 min at $4^{\circ} \mathrm{C}$. After quantification of total protein by BCA assay, equal amounts of total protein lysates $(25 \mu \mathrm{g})$ were resolved by SDS-PAGE and transferred onto PVDF membranes. Membranes were blocked in 5\% fat free milk and then probed with antibodies. The primary antibodies used for western blot analysis were pAKT Ser473, AKT, pS6 Ser240/244, pERK Thr202/Tyr204, ERK, AR, cleaved PARP, and GAPDH were from Cell Signaling Technologies (Danvers, MA, USA). For detection, enhanced chemilumines- 
cence ECL reagent (GE Healthcare, Pittsburgh, PA) was used and signals were visualized using the ChemiDoc XRS system (Bio-Rad).

MTT assay LNCaP and C4-2 cells were seeded at a density of $1 \times 10^{4}$ cells per well in 96 well plates. After $48 \mathrm{hrs}$ the media was refreshed and drug treatments added. Cell growth at 24,48 , and 72 hrs was determined using a 3-(4,5-dimethyl thiazol-2-yl)-2,5-diphenyl tetrazolium bromide (MTT) assay. At the specified time point $10 \mu \mathrm{L}$ MTT reagent (stock of $5 \mathrm{mg} / \mathrm{mL}$ in PBS) was added to each well and the cells were further incubated for $4 \mathrm{hrs}$. At $4 \mathrm{hrs}$, the media was removed and $50 \mu \mathrm{L}$ of dissolving reagent DMSO was added to each well. After an additional 10 min incubation, the absorbance was measured at 540 $\mathrm{nm}$ on a microplate reader. Each reading was adjusted by subtracting the absorbance value for the blank (media only) and the results were then scaled to the DMSO-treated (control) case.

\section{Acknowledgements}

This study was supported by award number U54CA143876 from the National Cancer Institute. The content is solely the responsibility of the authors and does not necessarily represent the official views of the National Cancer Institute or the National Institutes of Health. The authors acknowledge the financial support of the National Science Foundation, award no. DGE-1045513,for a GK12 training grant entitled G̈rass Roots: Advancing Education in Renewable Energy and Cleaner Fuels through collaborative graduate fellow/teacher/grade-school student interactions. Ẅe would like to thank Timothy Chu, Kyriakos Tsahalis, Spencer Davis, Rohit Yallamraju, Gongcheng Lu, and Yalin Zhao for model development, and cell culture studies. 


\section{References}

1. Abramoff M Magelhaes P RS (2004) Image processing with imagej. Biophotonics Int 11: $36-42$

2. Aranda A, Pascual A (2001) Nuclear and Hormone Receptors and Gene Expression. Physiological Reviews 81: 1269-1304

3. Attard G, de Bono JS (2009) Prostate cancer: PSA as an intermediate end point in clinical trials. Nat Rev Urol 6: 473-5

4. Brinkmann AO, Blok LJ, de Ruiter PE, Doesburg P, Steketee K, Berrevoets CA, Trapman J (1999) Mechanisms of androgen receptor activation and function. J Steroid Biochem Mol Biol 69: 307-13

5. Brown KS, Sethna JP (2003) Statistical mechanical approaches to models with many poorly known parameters. Phys Rev E Stat Nonlin Soft Matter Phys 68: 021904

6. Brunet A, Bonni A, Zigmond MJ, Lin MZ, Juo P, Hu LS, Anderson MJ, Arden KC, Blenis J, Greenberg ME (1999) Akt promotes cell survival by phosphorylating and inhibiting a Forkhead transcription factor. Cell 96: 857-68

7. Busà R, Paronetto MP, Farini D, Pierantozzi E, Botti F, Angelini DF, Attisani F, Vespasiani G, Sette C (2007) The RNA-binding protein Sam68 contributes to proliferation and survival of human prostate cancer cells. Oncogene 26: 4372-82

8. Cai C, Portnoy DC, Wang H, Jiang X, Chen S, Balk SP (2009) Androgen receptor expression in prostate cancer cells is suppressed by activation of epidermal growth factor receptor and ErbB2. Cancer Res 69: 5202-9

9. Cardillo MR, Monti S, Di Silverio F, Gentile V, Sciarra F, Toscano V (2003) Insulin-like growth factor (IGF)-I, IGF-II and IGF type I receptor (IGFR-I) expression in prostatic cancer. Anticancer Res 23: 3825-35

10. Carver BS, Chapinski C, Wongvipat J, Hieronymus H, Chen Y, Chandarlapaty S, Arora VK, Le C, Koutcher J, Scher H, Scardino PT, Rosen N, Sawyers CL (2011) 
Reciprocal feedback regulation of PI3K and androgen receptor signaling in PTENdeficient prostate cancer. Cancer Cell 19: 575-86

11. Chen L, Mooso BA, Jathal MK, Madhav A, Johnson SD, van Spyk E, Mikhailova M, Zierenberg-Ripoll A, Xue L, Vinall RL, deVere White RW, Ghosh PM (2011) Dual EGFR/HER2 inhibition sensitizes prostate cancer cells to androgen withdrawal by suppressing ErbB3. Clin Cancer Res 17: 6218-28

12. Chen S, Kesler CT, Paschal BM, Balk SP (2009) Androgen receptor phosphorylation and activity are regulated by an association with protein phosphatase 1. $\mathrm{J} \mathrm{Biol} \mathrm{Chem}$ 284: 25576-84

13. Chiu YT, Han HY, Leung SCL, Yuen HF, Chau CW, Guo Z, Qiu Y, Chan KW, Wang X, Wong YC, Ling MT (2009) CDC25A functions as a novel Ar corepressor in prostate cancer cells. J Mol Biol 385: 446-56

14. Chuang TD, Chen SJ, Lin FF, Veeramani S, Kumar S, Batra SK, Tu Y, Lin MF (2010) Human prostatic acid phosphatase, an authentic tyrosine phosphatase, dephosphorylates ErbB-2 and regulates prostate cancer cell growth. J Biol Chem 285: 23598606

15. Cinar B, De Benedetti A, Freeman MR (2005) Post-transcriptional regulation of the androgen receptor by Mammalian target of rapamycin. Cancer Res 65: 2547-53

16. Craft N, Shostak Y, Carey M, Sawyers CL (1999) A mechanism for hormoneindependent prostate cancer through modulation of androgen receptor signaling by the HER-2/neu tyrosine kinase. Nat Med 5: 280-5

17. Dahut WL, Scripture C, Posadas E, Jain L, Gulley JL, Arlen PM, Wright JJ, Yu Y, Cao L, Steinberg SM, Aragon-Ching JB, Venitz J, Jones E, Chen CC, Figg WD (2008) A phase II clinical trial of sorafenib in androgen-independent prostate cancer. Clin Cancer Res 14: 209-14

18. Davis JN, Wojno KJ, Daignault S, Hofer MD, Kuefer R, Rubin MA, Day ML (2006) 
Elevated E2F1 inhibits transcription of the androgen receptor in metastatic hormoneresistant prostate cancer. Cancer Res 66: 11897-906

19. de Bono JS, Oudard S, Ozguroglu M, Hansen S, Machiels JP, Kocak I, Gravis G, Bodrogi I, Mackenzie MJ, Shen L, Roessner M, Gupta S, Sartor AO, TROPIC Investigators (2010) Prednisone plus cabazitaxel or mitoxantrone for metastatic castrationresistant prostate cancer progressing after docetaxel treatment: a randomised openlabel trial. Lancet 376: 1147-54

20. Dickinson R, Gelinas R (1976) Sensitivity analysis of ordinary differential equation systems—A direct method. Journal of Computational Physics 21: 123-143

21. Fang Z, Zhang T, Dizeyi N, Chen S, Wang H, Swanson KD, Cai C, Balk SP, Yuan X (2012) Androgen Receptor Enhances p27 Degradation in Prostate Cancer Cells through Rapid and Selective TORC2 Activation. J Biol Chem 287: 2090-8

22. Feldman BJ, Feldman D (2001) The development of androgen-independent prostate cancer. Nat Rev Cancer 1: 34-45

23. Fonseca C FP (1993) Genetic algorithms for multiobjective optimization: Formulation, discussion and generalization. In Proceedings of the fifth international conference on genetic algorithms Citeseer 423: 416-423

24. Gadkar KG, Doyle 3rd FJ, Crowley TJ, Varner JD (2003) Cybernetic model predictive control of a continuous bioreactor with cell recycle. Biotechnol Prog 19: 1487-97

25. Gioeli D, Paschal BM (2012) Post-translational modification of the androgen receptor. Mol Cell Endocrinol 352: 70-8

26. Graff JR, Konicek BW, Lynch RL, Dumstorf CA, Dowless MS, McNulty AM, Parsons SH, Brail LH, Colligan BM, Koop JW, Hurst BM, Deddens JA, Neubauer BL, Stancato LF, Carter HW, Douglass LE, Carter JH (2009) elF4E activation is commonly elevated in advanced human prostate cancers and significantly related to reduced patient survival. Cancer Res 69: 3866-73 
27. Graff JR, Konicek BW, McNulty AM, Wang Z, Houck K, Allen S, Paul JD, Hbaiu A, Goode RG, Sandusky GE, Vessella RL, Neubauer BL (2000) Increased AKT activity contributes to prostate cancer progression by dramatically accelerating prostate tumor growth and diminishing p27Kip1 expression. J Biol Chem 275: 24500-5

28. Gregory CW, Fei X, Ponguta LA, He B, Bill HM, French FS, Wilson EM (2004) Epidermal growth factor increases coactivation of the androgen receptor in recurrent prostate cancer. J Biol Chem 279: 7119-30

29. Gregory CW, He B, Johnson RT, Ford OH, Mohler JL, French FS, Wilson EM (2001) A mechanism for androgen receptor-mediated prostate cancer recurrence after androgen deprivation therapy. Cancer Res 61: 4315-9

30. Guo Z, Dai B, Jiang T, Xu K, Xie Y, Kim O, Nesheiwat I, Kong X, Melamed J, Handratta VD, Njar VCO, Brodie AMH, Yu LR, Veenstra TD, Chen H, Qiu Y (2006) Regulation of androgen receptor activity by tyrosine phosphorylation. Cancer Cell 10: 309-19

31. Ha S, Ruoff R, Kahoud N, Franke TF, Logan SK (2011) Androgen receptor levels are upregulated by Akt in prostate cancer. Endocr Relat Cancer 18: 245-55

32. Hakariya T, Shida Y, Sakai H, Kanetake H, Igawa T (2006) EGFR signaling pathway negatively regulates PSA expression and secretion via the PI3K-Akt pathway in LNCaP prostate cancer cells. Biochem Biophys Res Commun 342: 92-100

33. Handl J, Kell DB, Knowles J (2007) Multiobjective optimization in bioinformatics and computational biology. IEEEACM Trans Comput Biol Bioinform 4: 279-92

34. Harris WP, Mostaghel EA, Nelson PS, Montgomery B (2009) Androgen deprivation therapy: progress in understanding mechanisms of resistance and optimizing androgen depletion. Nat Clin Pract Urol 6: 76-85

35. Heemers HV, Tindall DJ (2007) Androgen receptor (AR) coregulators: a diversity of functions converging on and regulating the AR transcriptional complex. Endocr Rev 28: $778-808$ 
36. Heinlein CA, Chang C (2002) Androgen receptor (AR) coregulators: an overview. Endocr Rev 23: 175-200

37. Heinlein CA, Chang C (2004) Androgen receptor in prostate cancer. Endocr Rev 25 : 276-308

38. Hendriks BS, Opresko LK, Wiley HS, Lauffenburger D (2003) Quantitative analysis of HER2-mediated effects on HER2 and epidermal growth factor receptor endocytosis: distribution of homo- and heterodimers depends on relative HER2 levels. J Biol Chem 278: $23343-51$

39. Hindmarsh A, Brown P, Grant K, Lee S, Serban R, Shumaker D, Woodward C (2005) SUNDIALS: Suite of nonlinear and differential/algebraic equation solvers. ACM Transactions on Mathematical Software 31: 363-396

40. Hoffman RM (2011) Clinical practice. Screening for prostate cancer. N Engl J Med 365: 2013-9

41. Horoszewicz JS, Leong SS, Kawinski E, Karr JP, Rosenthal H, Chu TM, Mirand EA, Murphy GP (1983) LNCaP model of human prostatic carcinoma. Cancer Res 43: $1809-18$

42. Huggins C (1967) Endocrine-induced regression of cancers. Cancer Res 27: 192530

43. Igawa T, Lin FF, Lee MS, Karan D, Batra SK, Lin MF (2002) Establishment and characterization of androgen-independent human prostate cancer LNCaP cell model. Prostate 50: 222-35

44. Kantoff PW, Higano CS, Shore ND, Berger ER, Small EJ, Penson DF, Redfern CH, Ferrari AC, Dreicer R, Sims RB, Xu Y, Frohlich MW, Schellhammer PF, IMPACT Study Investigators (2010) Sipuleucel-T immunotherapy for castration-resistant prostate cancer. N Engl J Med 363: 411-22

45. Karantanos T, Corn PG, Thompson TC (2013) Prostate cancer progression after an- 
drogen deprivation therapy: mechanisms of castrate resistance and novel therapeutic approaches. Oncogene

46. Knudsen KE, Arden KC, Cavenee WK (1998) Multiple G1 regulatory elements control the androgen-dependent proliferation of prostatic carcinoma cells. J Biol Chem 273: 20213-22

47. Lee MS, Igawa T, Lin MF (2004) Tyrosine-317 of p52(Shc) mediates androgenstimulated proliferation signals in human prostate cancer cells. Oncogene 23: 304858

48. Lee MS, Igawa T, Yuan TC, Zhang XQ, Lin FF, Lin MF (2003) ErbB-2 signaling is involved in regulating PSA secretion in androgen-independent human prostate cancer LNCaP C-81 cells. Oncogene 22: 781-96

49. Lequieu J, Chakrabarti A, Nayak S, Varner JD (2011) Computational modeling and analysis of insulin induced eukaryotic translation initiation. PLoS Comput Biol 7: e1002263

50. Lim JTE, Mansukhani M, Weinstein IB (2005) Cyclin-dependent kinase 6 associates with the androgen receptor and enhances its transcriptional activity in prostate cancer cells. Proc Natl Acad Sci U S A 102: 5156-61

51. Lin HK, Hu YC, Yang L, Altuwaijri S, Chen YT, Kang HY, Chang C (2003) Suppression versus induction of androgen receptor functions by the phosphatidylinositol 3kinase/Akt pathway in prostate cancer LNCaP cells with different passage numbers. J Biol Chem 278: 50902-7

52. Lin HK, Yeh S, Kang HY, Chang C (2001) Akt suppresses androgen-induced apoptosis by phosphorylating and inhibiting androgen receptor. Proc Natl Acad Sci U S A 98: $7200-5$

53. Lin MF, Lee MS, Garcia-Arenas R, Lin FF (2000) Differential responsiveness of prostatic acid phosphatase and prostate-specific antigen mRNA to androgen in prostate 
cancer cells. Cell Biol Int 24: 681-9

54. Lin MF, Lee MS, Zhou XW, Andressen JC, Meng TC, Johansson SL, West WW, Taylor RJ, Anderson JR, Lin FF (2001) Decreased expression of cellular prostatic acid phosphatase increases tumorigenicity of human prostate cancer cells. J Urol 166: $1943-50$

55. Liu G, Chen YH, Kolesar J, Huang W, Dipaola R, Pins M, Carducci M, Stein M, Bubley GJ, Wilding G (2013) Eastern Cooperative Oncology Group Phase II Trial of lapatinib in men with biochemically relapsed, androgen dependent prostate cancer. Urol Oncol 31: $211-8$

56. Liu Y, Majumder S, McCall W, Sartor Cl, Mohler JL, Gregory CW, Earp HS, Whang YE (2005) Inhibition of HER-2/neu kinase impairs androgen receptor recruitment to the androgen responsive enhancer. Cancer Res 65: 3404-9

57. Lu S, Tsai SY, Tsai MJ (1997) Regulation of androgen-dependent prostatic cancer cell growth: androgen regulation of CDK2, CDK4, and CKI p16 genes. Cancer Res 57: $4511-6$

58. Mangelsdorf DJ, Thummel C, Beato M, Herrlich P, Schütz G, Umesono K, Blumberg B, Kastner P, Mark M, Chambon P, Evans RM (1995) The nuclear receptor superfamily: the second decade. Cell 83: 835-9

59. Medema RH, Kops GJ, Bos JL, Burgering BM (2000) AFX-like Forkhead transcription factors mediate cell-cycle regulation by Ras and PKB through p27kip1. Nature 404: $782-7$

60. Meng TC, Lee MS, Lin MF (2000) Interaction between protein tyrosine phosphatase and protein tyrosine kinase is involved in androgen-promoted growth of human prostate cancer cells. Oncogene 19: 2664-77

61. Moyer VA, U.S. Preventive Services Task Force (2012) Screening for prostate cancer: U.S. Preventive Services Task Force recommendation statement. Ann Intern Med 


\section{7: 120-34}

62. Murillo H, Huang H, Schmidt LJ, Smith DI, Tindall DJ (2001) Role of PI3K signaling in survival and progression of LNCaP prostate cancer cells to the androgen refractory state. Endocrinology 142: 4795-805

63. Ngan ESW, Hashimoto Y, Ma ZQ, Tsai MJ, Tsai SY (2003) Overexpression of Cdc25B, an androgen receptor coactivator, in prostate cancer. Oncogene 22: 734-9

64. Parker C, Nilsson S, Heinrich D, Helle SI, O'Sullivan JM, Fosså SD, Chodacki A, Wiechno P, Logue J, Seke M, Widmark A, Johannessen DC, Hoskin P, Bottomley D, James ND, Solberg A, Syndikus I, Kliment J, Wedel S, Boehmer S, et al (2013) Alpha emitter radium-223 and survival in metastatic prostate cancer. $N$ Engl J Med 369: 213-23

65. Paronetto MP, Cappellari M, Busà R, Pedrotti S, Vitali R, Comstock C, Hyslop T, Knudsen KE, Sette C (2010) Alternative splicing of the cyclin D1 proto-oncogene is regulated by the RNA-binding protein Sam68. Cancer Res 70: 229-39

66. Perry JE, Grossmann ME, Tindall DJ (1998) Epidermal growth factor induces cyclin D1 in a human prostate cancer cell line. Prostate 35: 117-24

67. Petre-Draviam CE, Cook SL, Burd CJ, Marshall TW, Wetherill YB, Knudsen KE (2003) Specificity of cyclin D1 for androgen receptor regulation. Cancer Res 63: 4903-13

68. Ponguta LA, Gregory CW, French FS, Wilson EM (2008) Site-specific androgen receptor serine phosphorylation linked to epidermal growth factor-dependent growth of castration-recurrent prostate cancer. J Biol Chem 283: 20989-1001

69. Pratt WB, Toft DO (1997) Steroid receptor interactions with heat shock protein and immunophilin chaperones. Endocr Rev 18: 306-60

70. Prescott J, Coetzee GA (2006) Molecular chaperones throughout the life cycle of the androgen receptor. Cancer Lett 231: 12-9

71. Rodríguez-Ubreva FJ, Cariaga-Martinez AE, Cortés MA, Romero-De Pablos M, 
Ropero S, López-Ruiz P, Colás B (2010) Knockdown of protein tyrosine phosphatase SHP-1 inhibits G1/S progression in prostate cancer cells through the regulation of components of the cell-cycle machinery. Oncogene 29: 345-55

72. Sartor O, Pal SK (2013) Abiraterone and its place in the treatment of metastatic CRPC. Nat Rev Clin Oncol 10: 6-8

73. Sato N, Sadar MD, Bruchovsky N, Saatcioglu F, Rennie PS, Sato S, Lange PH, Gleave ME (1997) Androgenic induction of prostate-specific antigen gene is repressed by protein-protein interaction between the androgen receptor and AP-1/c-Jun in the human prostate cancer cell line LNCaP. J Biol Chem 272: 17485-94

74. Scher HI, Fizazi K, Saad F, Taplin ME, Sternberg CN, Miller K, de Wit R, Mulders P, Chi KN, Shore ND, Armstrong AJ, Flaig TW, Fléchon A, Mainwaring P, Fleming M, Hainsworth JD, Hirmand M, Selby B, Seely L, de Bono JS, et al (2012) Increased survival with enzalutamide in prostate cancer after chemotherapy. N Engl J Med 367: $1187-97$

75. Seaton A, Scullin P, Maxwell PJ, Wilson C, Pettigrew J, Gallagher R, O'Sullivan JM, Johnston PG, Waugh DJJ (2008) Interleukin-8 signaling promotes androgenindependent proliferation of prostate cancer cells via induction of androgen receptor expression and activation. Carcinogenesis 29: 1148-56

76. Sharma A, Yeow WS, Ertel A, Coleman I, Clegg N, Thangavel C, Morrissey C, Zhang X, Comstock CES, Witkiewicz AK, Gomella L, Knudsen ES, Nelson PS, Knudsen KE (2010) The retinoblastoma tumor suppressor controls androgen signaling and human prostate cancer progression. J Clin Invest 120: 4478-92

77. Sherr CJ, Roberts JM (1999) CDK inhibitors: positive and negative regulators of G1phase progression. Genes Dev 13: 1501-12

78. Siegel R, Naishadham D, Jemal A (2013) Cancer statistics, 2013. CA Cancer J Clin 63: $11-30$ 
79. Slamon DJ, Godolphin W, Jones LA, Holt JA, Wong SG, Keith DE, Levin WJ, Stuart SG, Udove J, Ullrich A (1989) Studies of the HER-2/neu proto-oncogene in human breast and ovarian cancer. Science 244: 707-12

80. Sobel RE, Sadar MD (2005) Cell lines used in prostate cancer research: a compendium of old and new lines-part 1. J Urol 173: 342-59

81. Song SO, Chakrabarti A, Varner JD (2010) Ensembles of signal transduction models using Pareto Optimal Ensemble Techniques (POETs). Biotechnol J 5: 768-80

82. Song SO, Varner J (2009) Modeling and analysis of the molecular basis of pain in sensory neurons. PLoS One 4: e6758

83. Takaishi H, Konishi H, Matsuzaki H, Ono Y, Shirai Y, Saito N, Kitamura T, Ogawa W, Kasuga M, Kikkawa U, Nishizuka Y (1999) Regulation of nuclear translocation of forkhead transcription factor AFX by protein kinase B. Proc Natl Acad Sci U S A 96: 11836-41

84. Tam L, McGlynn LM, Traynor P, Mukherjee R, Bartlett JMS, Edwards J (2007) Expression levels of the JAK/STAT pathway in the transition from hormone-sensitive to hormone-refractory prostate cancer. Br J Cancer 97: 378-83

85. Taneja SS, Ha S, Swenson NK, Huang HY, Lee P, Melamed J, Shapiro E, Garabedian MJ, Logan SK (2005) Cell-specific regulation of androgen receptor phosphorylation in vivo. J Biol Chem 280: 40916-24

86. Tannock IF, de Wit R, Berry WR, Horti J, Pluzanska A, Chi KN, Oudard S, Théodore C, James ND, Turesson I, Rosenthal MA, Eisenberger MA, TAX 327 Investigators (2004) Docetaxel plus prednisone or mitoxantrone plus prednisone for advanced prostate cancer. N Engl J Med 351: 1502-12

87. Tasseff R, Nayak S, Salim S, Kaushik P, Rizvi N, Varner JD (2010) Analysis of the molecular networks in androgen dependent and independent prostate cancer revealed fragile and robust subsystems. PLoS One 5: e8864 
88. Tasseff R, Nayak S, Song SO, Yen A, Varner JD (2011) Modeling and analysis of retinoic acid induced differentiation of uncommitted precursor cells. Integr Biol Camb 3: $578-91$

89. Veeramani S, Igawa T, Yuan TC, Lin FF, Lee MS, Lin JS, Johansson SL, Lin MF (2005) Expression of p66(Shc) protein correlates with proliferation of human prostate cancer cells. Oncogene 24: 7203-12

90. Veeramani S, Yuan TC, Chen SJ, Lin FF, Petersen JE, Shaheduzzaman S, Srivastava S, MacDonald RG, Lin MF (2005) Cellular prostatic acid phosphatase: a protein tyrosine phosphatase involved in androgen-independent proliferation of prostate cancer. Endocr Relat Cancer 12: 805-22

91. Weber MJ, Gioeli D (2004) Ras signaling in prostate cancer progression. J Cell Biochem 91: 13-25

92. Wen Y, Hu MC, Makino K, Spohn B, Bartholomeusz G, Yan DH, Hung MC (2000) HER-2/neu promotes androgen-independent survival and growth of prostate cancer cells through the Akt pathway. Cancer Res 60: 6841-5

93. Whang YE, Armstrong AJ, Rathmell WK, Godley PA, Kim WY, Pruthi RS, Wallen EM, Crane JM, Moore DT, Grigson G, Morris K, Watkins CP, George DJ (2013) A phase II study of lapatinib, a dual EGFR and HER-2 tyrosine kinase inhibitor, in patients with castration-resistant prostate cancer. Urol Oncol 31: 82-6

94. Xu Y, Chen SY, Ross KN, Balk SP (2006) Androgens induce prostate cancer cell proliferation through mammalian target of rapamycin activation and post-transcriptional increases in cyclin D proteins. Cancer Res 66: 7783-92

95. Yamamoto A, Hashimoto Y, Kohri K, Ogata E, Kato S, Ikeda K, Nakanishi M (2000) Cyclin E as a coactivator of the androgen receptor. J Cell Biol 150: 873-80

96. Yeh S, Lin HK, Kang HY, Thin TH, Lin MF, Chang C (1999) From HER2/Neu signal cascade to androgen receptor and its coactivators: a novel pathway by induction of 
androgen target genes through MAP kinase in prostate cancer cells. Proc Natl Acad Sci U S A 96: 5458-63

97. Yeh S, Miyamoto H, Nishimura K, Kang H, Ludlow J, Hsiao P, Wang C, Su C, Chang C (1998) Retinoblastoma, a tumor suppressor, is a coactivator for the androgen receptor in human prostate cancer DU145 cells. Biochem Biophys Res Commun 248: 361-7

98. Yuan TC, Lin FF, Veeramani S, Chen SJ, Earp 3rd HS, Lin MF (2007) ErbB-2 via PYK2 upregulates the adhesive ability of androgen receptor-positive human prostate cancer cells. Oncogene 26: 7552-9 


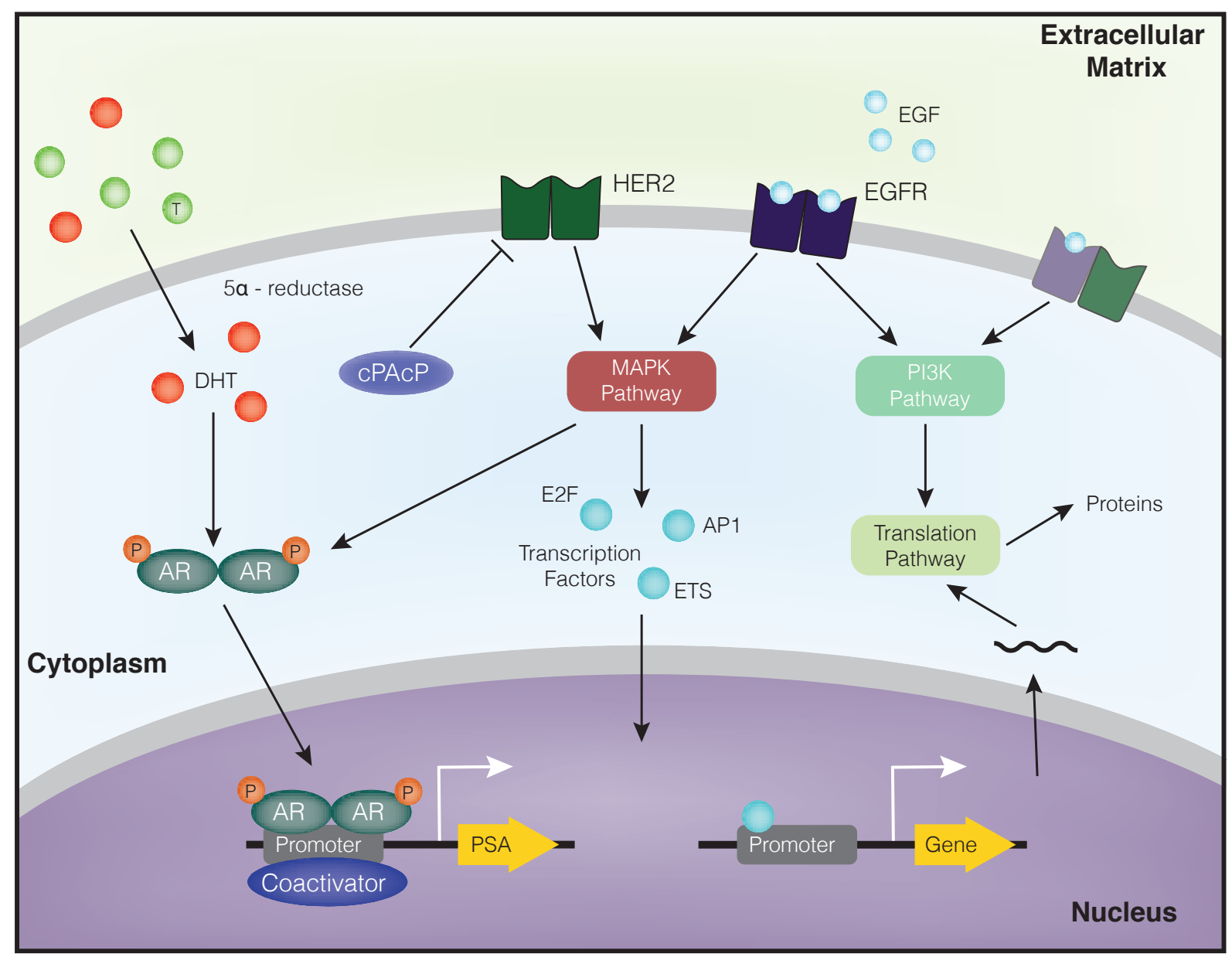

Fig. 1: Schematic overview of the prostate signaling network. The model describes hormone and growth factor induced expression of several proteins, including PSA. In the absence of outside hormones/growth factors, overactive HER2 can stimulate the MAPK and AKT pathways. AR can be activated directly by the MAPK pathway. 

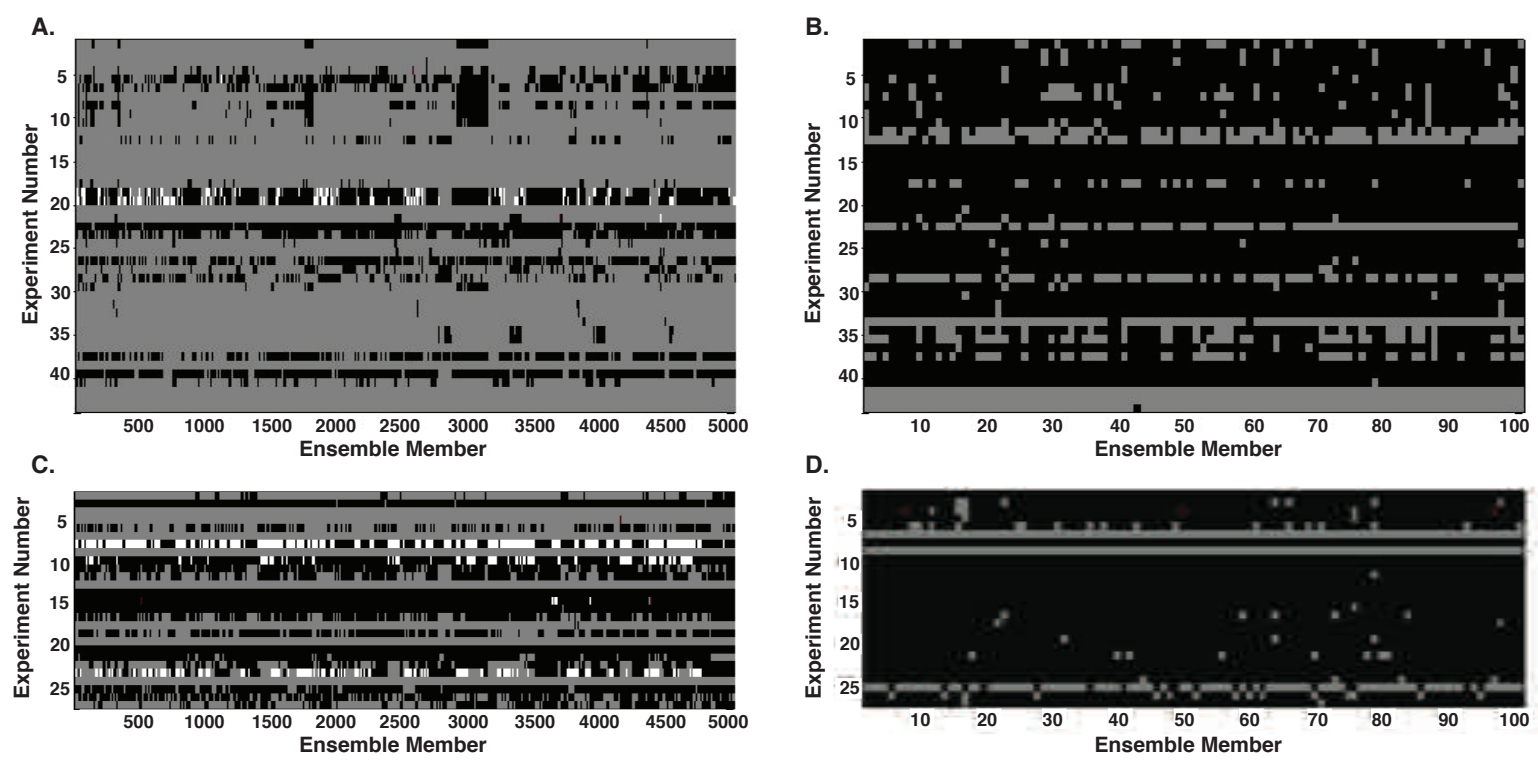

Fig. 2: Simulation results versus experimental results for training and validation data. Experiment numbers 1 through 43 were used for training, while experiments 44 through 72 were validation. Gray means the ensemble member qualitatively fit experimental data in both models. White means the the ensemble member only fit the data using the new model that included HER2 heterodimerization. Red means the ensemble member fit using only the old model. Black corresponds to an incorrect cellular response in both models. A., C. Training and validation results, respectively, for entire ensemble population using both the original model and an updated model including HER2 heterodimerization $(\mathrm{N}=5000)$. B., D. Simulation results for training and validation of a random set of 100 members using both models. 
A.

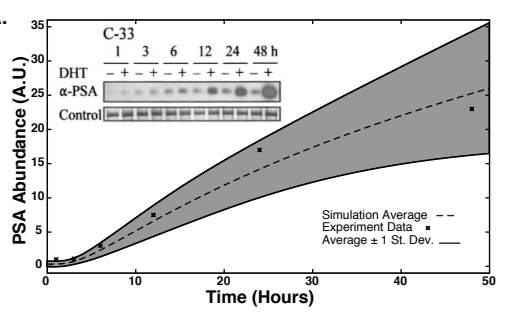

D.

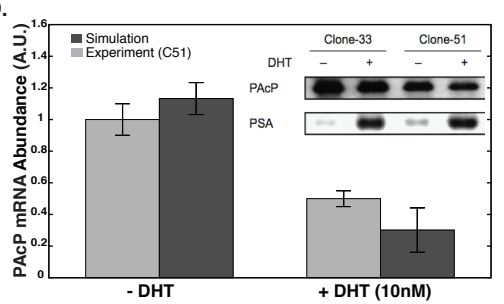

G.

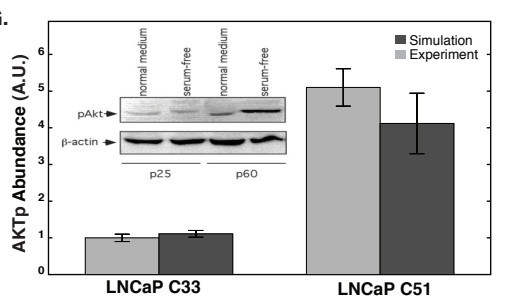

B.

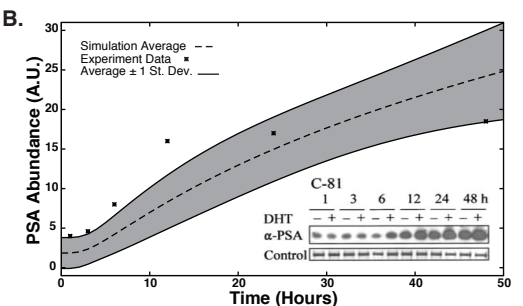

E.

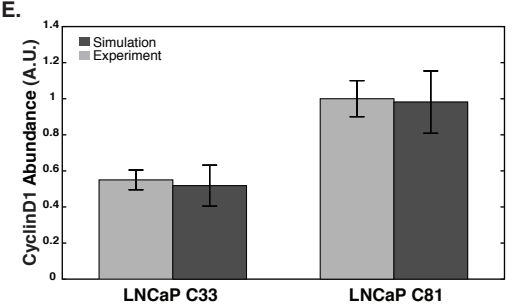

H.

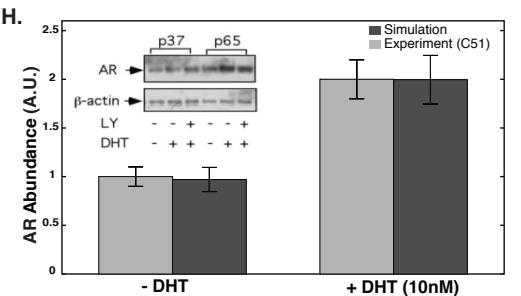

c.
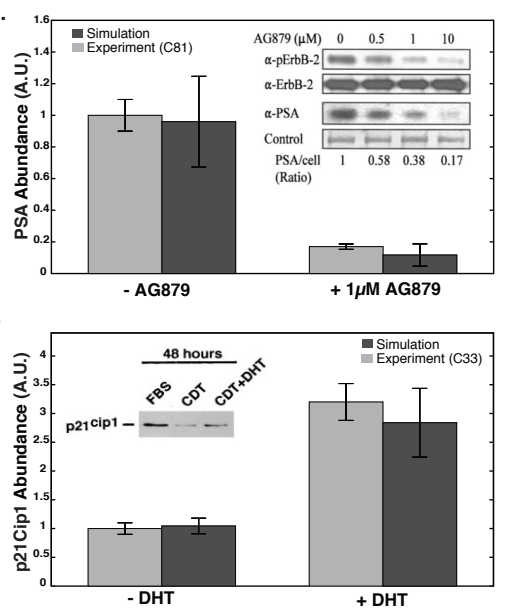

I.

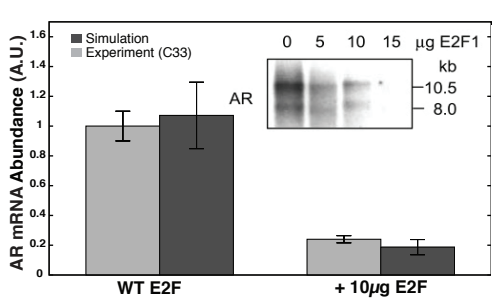

Fig. 3: Ensemble performance against selected training objectives $(N=5000)$. A, B. Time course data for PSA concentration due to a stimulus of $10 \mathrm{nM}$ DHT in LNCaP C33 cells and LNCaP C81 cells, respectively $(\mathrm{O} 2, \mathrm{O} 3)$. C. PSA levels in the presence and absence of a HER2 inhibitor (LNCaP C81 cells, O7). D. PAcP mRNA levels at 72 hours in the presence and absence of DHT (LNCaP C51 cells, O14). E. Steady-state cyclin D levels in LNCaP C33 vs. C81 (O17). F. p21Cip1 levels at $48 \mathrm{hrs}$ in the presence and absence of DHT (LNCaP C33, O25). G. Steady-state AKT phosphorylation levels in LNCaP C33 vs. C51 (O30). H. AR levels at 24 hours in the presence and absence of DHT (LNCaP C51, O31). I. AR mRNA levels in the presence and absence of E2F over expression ( $\mathrm{LNCaP} \mathrm{C33,} \mathrm{O34).} \mathrm{Error} \mathrm{bars} \mathrm{denote} \mathrm{plus} \mathrm{and} \mathrm{minus} \mathrm{one}$ standard deviation from the mean. 
A.

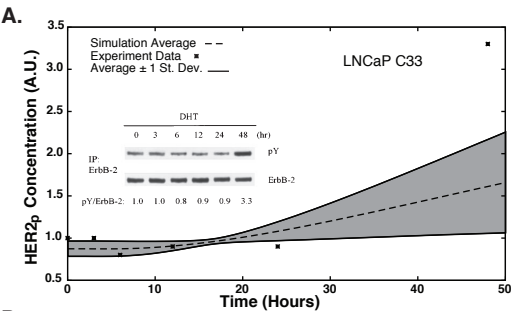

D.
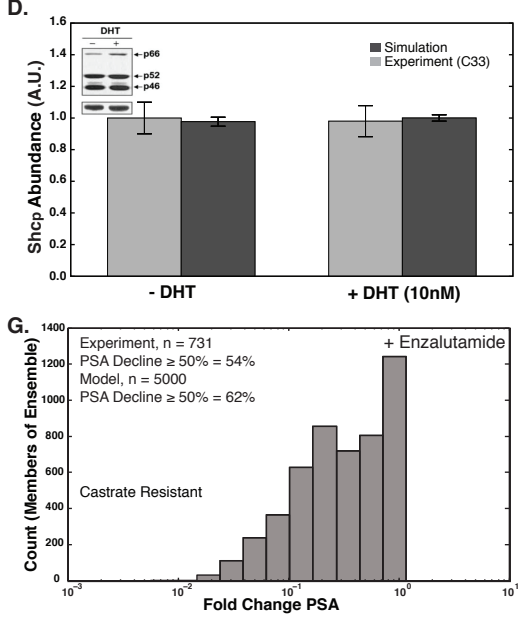

B.

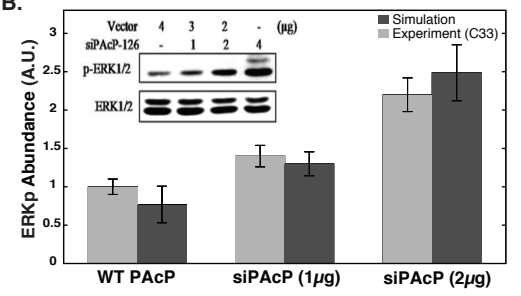

E.
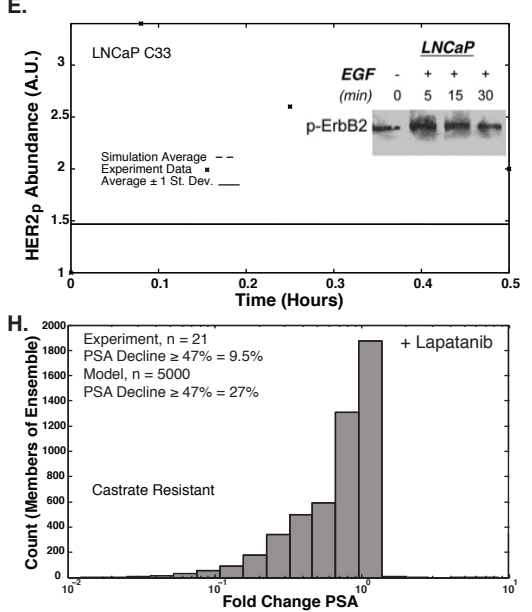

c.

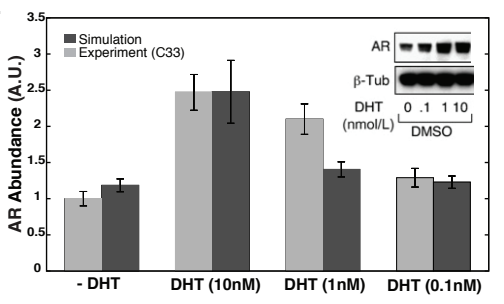

F.
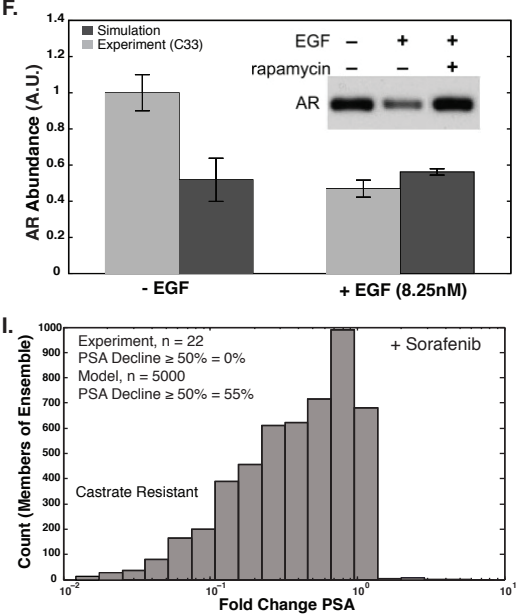

Fig. 4: Blind model predictions for the ensemble $(N=5000)$. The model ensemble's predictive ability was assessed by comparing simulation versus experimental data not used for training. A. Time course data for HER2 phosphorylation due to a stimulus of $10 \mathrm{nM} \mathrm{DHT} \mathrm{(LNCaP} \mathrm{C33,} \mathrm{P1).} \mathrm{B.} \mathrm{ERK} \mathrm{phosphorylation} \mathrm{levels}$ in the presence and absence of a PAcP inhibitor (LNCaP C33 cells, P3). C. AR levels at $24 \mathrm{hrs}$ in varying levels of DHT (LNCaP C33, P17). D. Shc phosphorylation levels at $24 \mathrm{hrs}$ in the presence and absence of DHT (LNCaP C33, P22). E. Time course data for HER2 phosphorylation due to a stimulus of $1.6 \mathrm{nM}$ EGF (LNCaP C33, P7). F. AR levels in varying levels of EGF (LNCaP C33, P14). G, H, I. Fold change in PSA concentration due to drug stimulus: enzalutamide, lapatinib, and sorafenib. Error bars denote plus and minus one standard deviation from the mean. 
A.

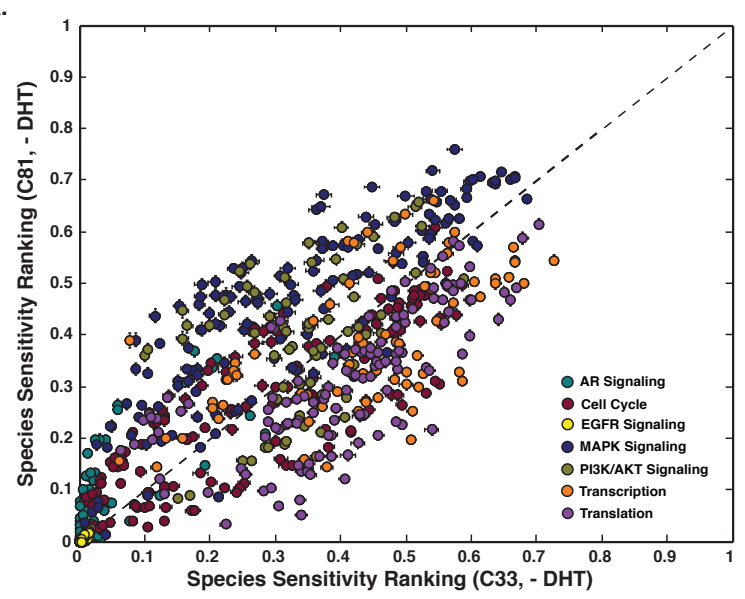

C.

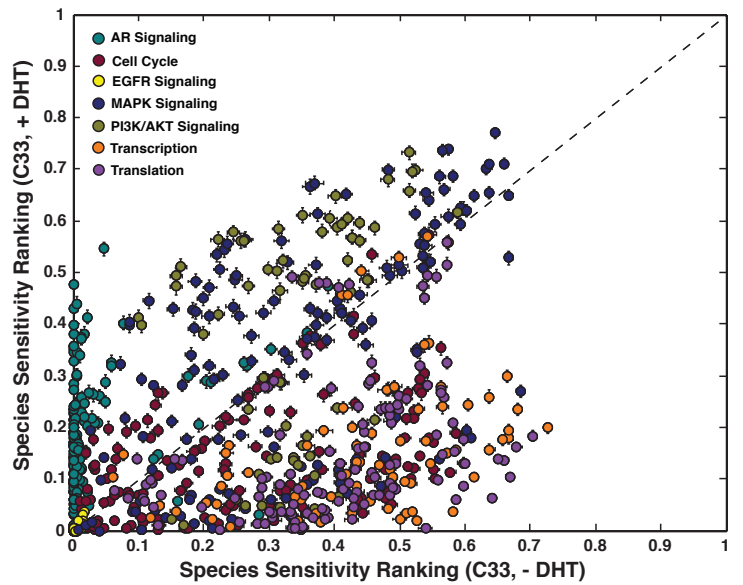

B.

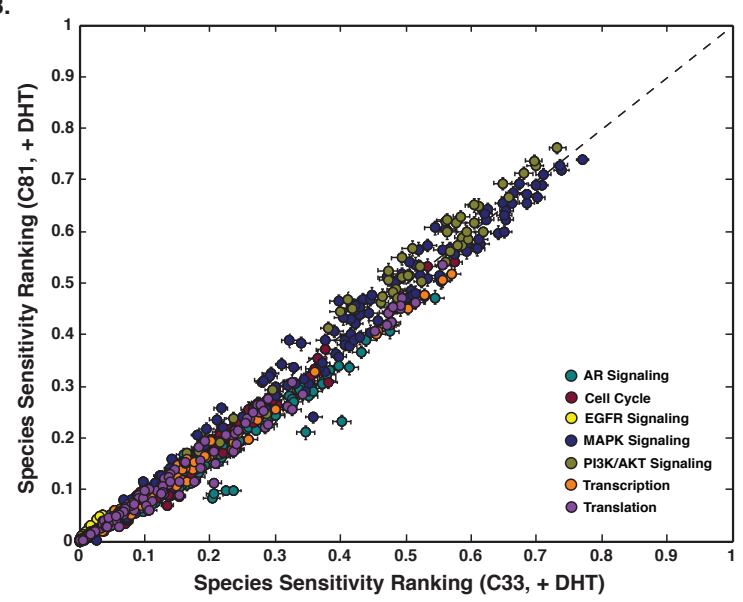

D.

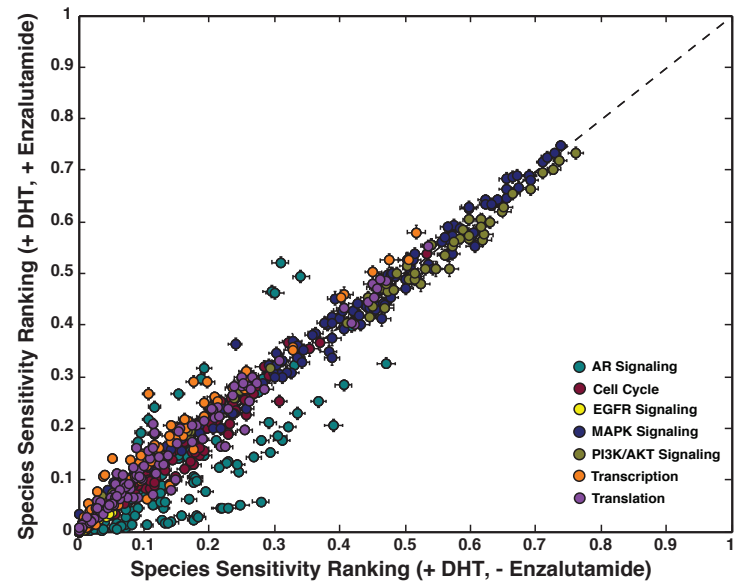

Fig. 5: Sensitivity analysis of a population of prostate models $(N=500)$. Species with a low sensitivity are considered robust, while species with a high sensitivity ranking are considered fragile. A, B. Sensitivity ranking of network species in $A D$ versus $C R$ cells in the absence (presence) of DHT. C. Sensitivity ranking of network species in AD cells in the absence and presence of DHT. D. Sensitivity ranking of network species in CR cells in the presence and absence of enzalutamide with a DHT stimulus. Error bars denote standard error with $\mathrm{N}=500$. 
A.

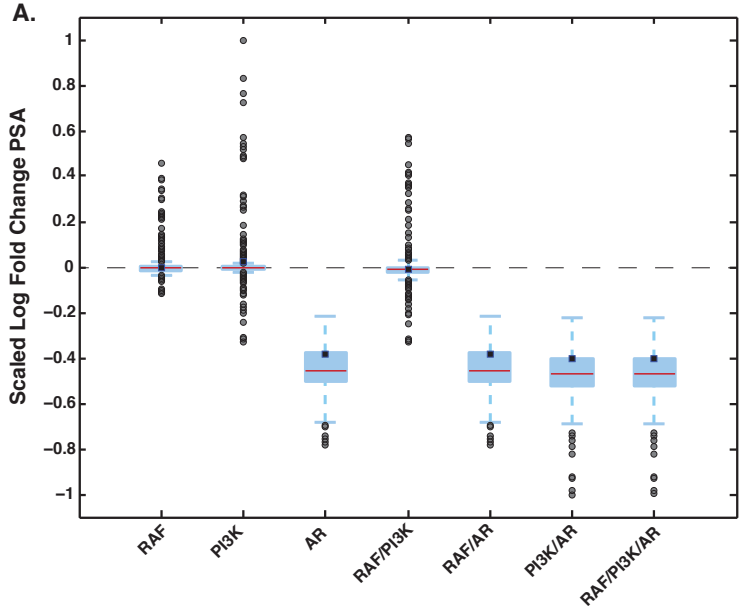

c.

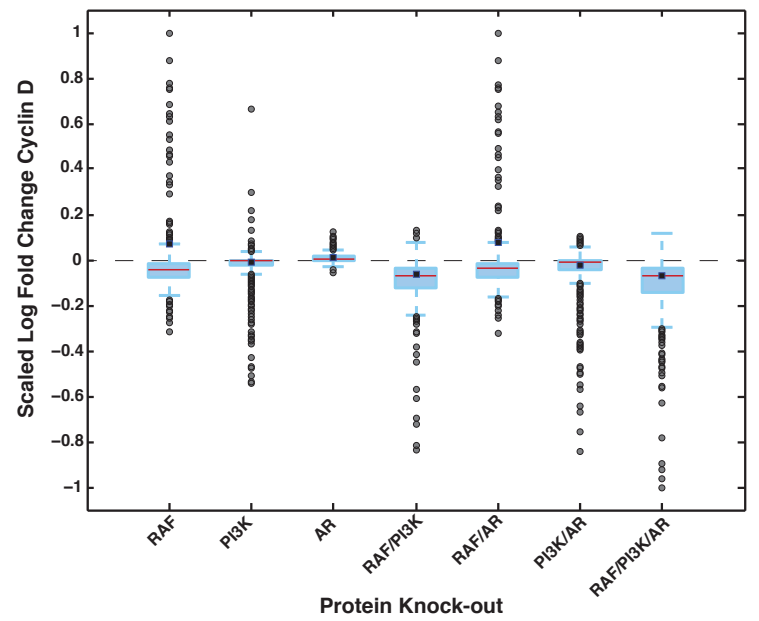

B.

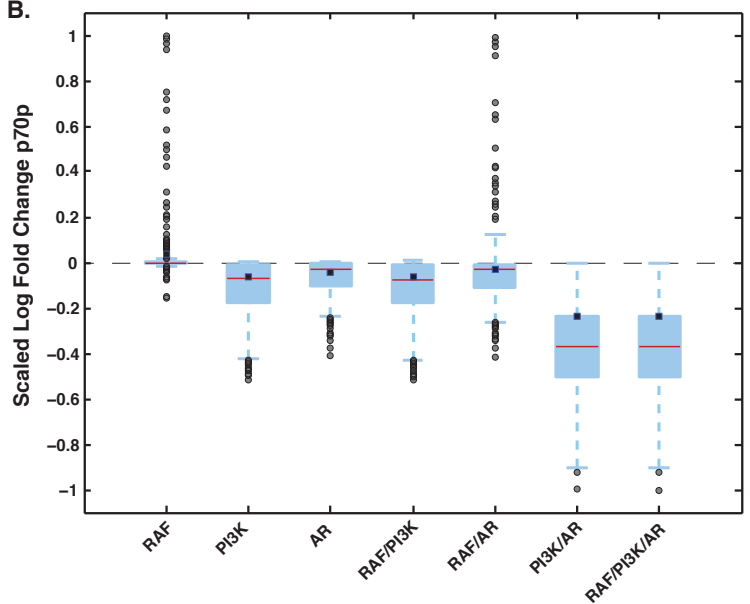

D.

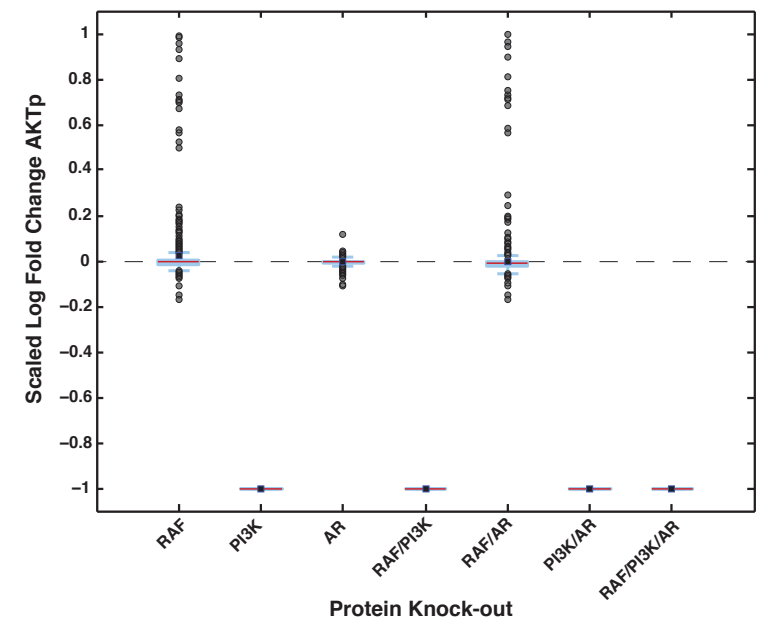

Fig. 6: Robustness analysis of a population of $\mathrm{CR}$ prostate models with seven protein knock-out cases $(\mathrm{N}$ $=500$ ). A scaled log fold change of greater than zero implies that the concentration of the protein increased with the knock-out, while a scaled log fold change of less than zero indicates that the concentration of protein decreased. A scaled log fold change equal to 0 , shows no response due to the knock-out. A.,B.,C.,D. Log robustness of PSA, p70p, cyclin D, and AKTp versus protein knock-out. A CR LNCaP cell was assumed for all knock-out cases. The bottom and top of each box denotes 25th and 75th percentiles, while the red line indicates the median. The whiskers on the plot are plus and minus 1.5 the interquartile range (IQR) from the top and bottom values of the box, respectively. The grey dots denote outliers and the blue dots denote the mean. 


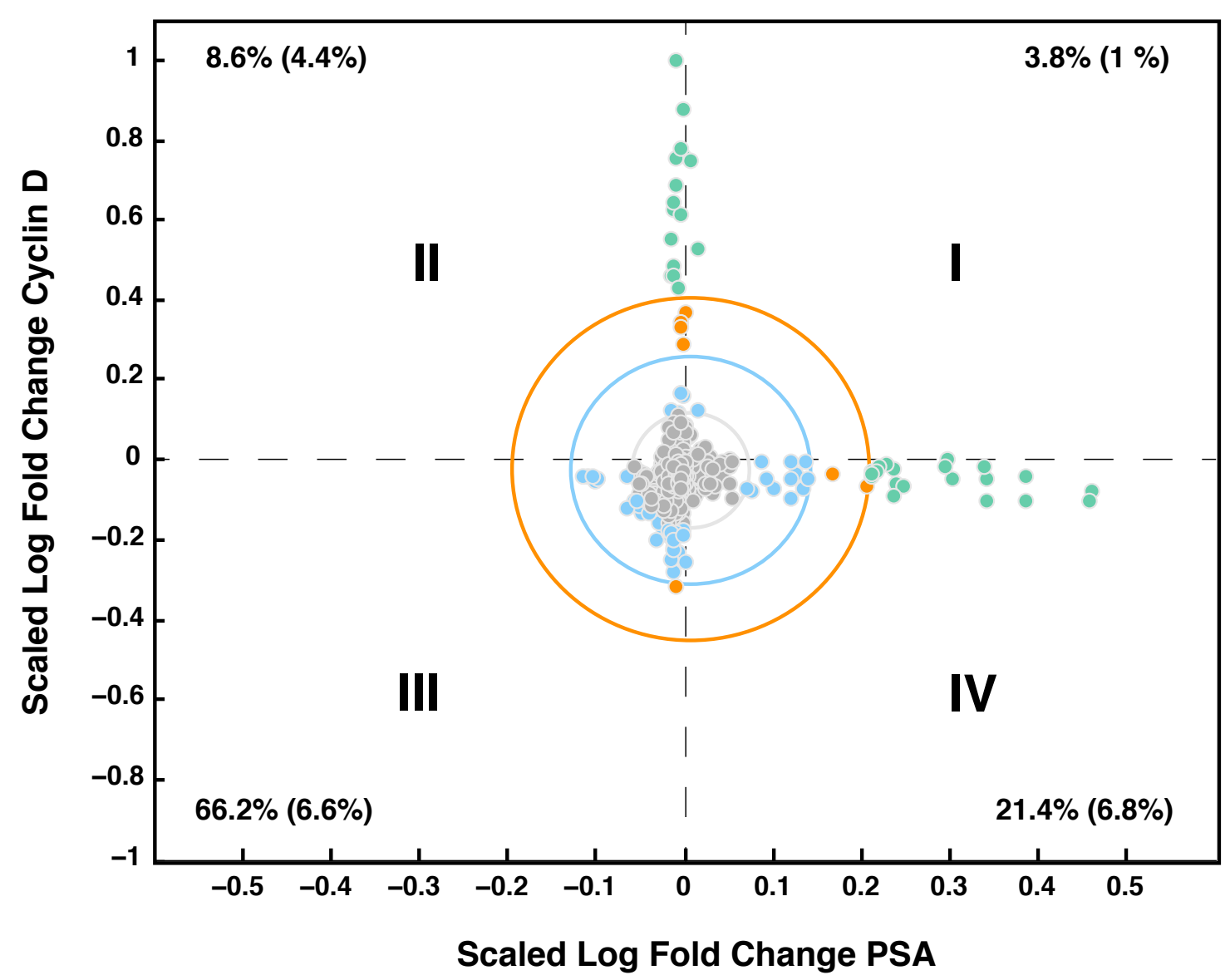

Fig. 7: Robustness analysis of a population of $C R$ prostate models with Raf knock-out $(N=500)$. A scaled log fold change of greater than zero implies that the concentration of the protein increased with the knockout of Raf, while a log fold change of less than zero indicates that the concentration of protein decreased. A log of fold change equal to 0 , shows no response due to Raf knock-out. Three distinct regions emerge in Raf knock-out case: (1) PSA increases, (2) cyclin D concentration increases, and (3) PSA and cyclin $D$ concentration decrease. The grey ellipse is centered at the mean values with an $x$-radius and $y$-radius of one standard deviation of the scaled log fold change of PSA values and cyclin D values, respectively. The blue ellipse denotes two standard deviations from the mean and the orange denotes three standard deviations from the mean. Values denote percentage of total parameter sets that fall in each quadrant, while values in parenthesis denote the percentage that fall at least one standard deviation from the mean. 

aCC-BY 4.0 International license.

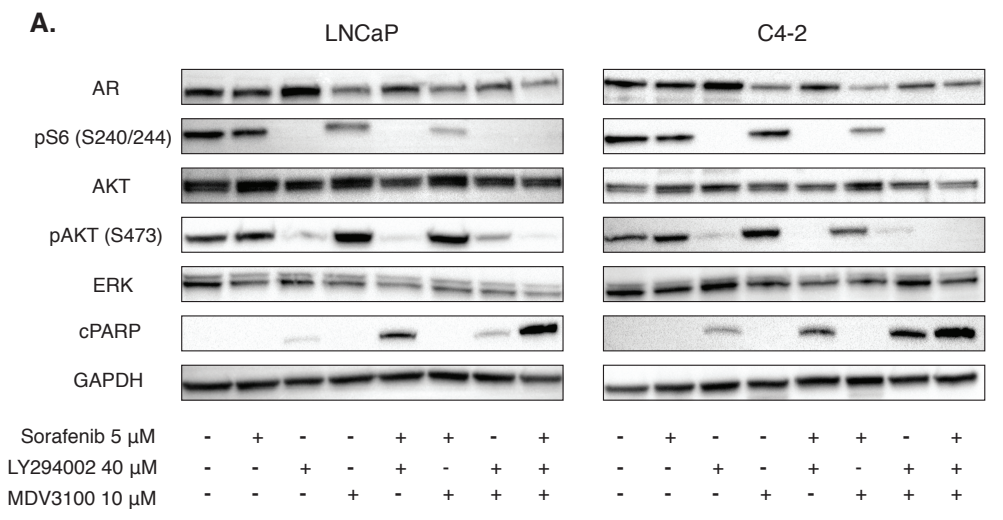

B.
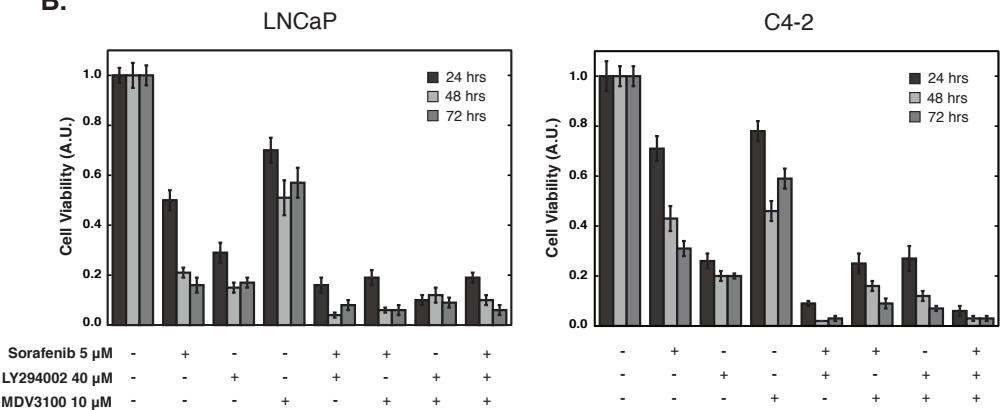

C.
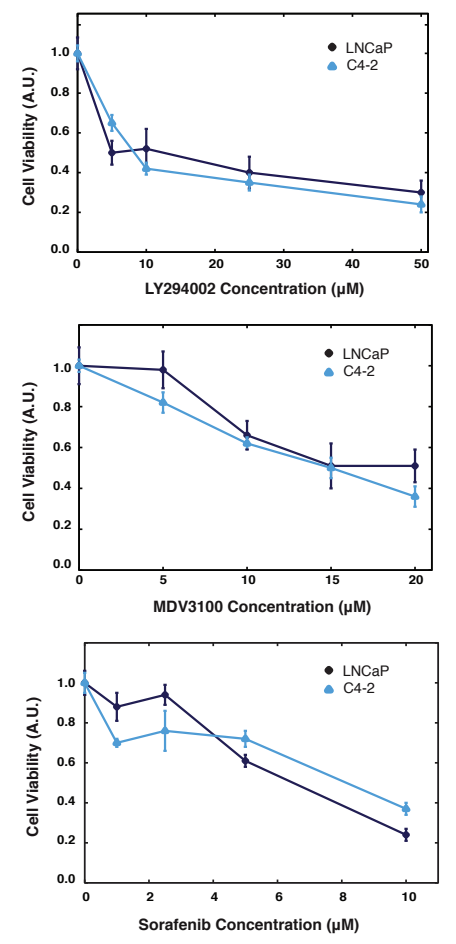

Fig. 8: Experimental results for multiple drug combinations on two prostate cancer cell lines, LNCaP and C4-2. A. Western blot analysis of AR, pS6, AKT, pAKT, ERK and cleaved PARP in LNCaP and C4-2 cell lines treated for $24 \mathrm{hrs}$ with DMSO (control), sorafenib $(5 \mu \mathrm{M})$, LY294002 $(40 \mu \mathrm{M})$, and MDV3100 $(10 \mu \mathrm{M})$ alone or in combination (at least 3 repeats). B. Cells (LNCaP and C4-2) were treated for 24, 48 and 72 hrs with sorafenib $(5 \mu \mathrm{M})$, LY294002 $(40 \mu \mathrm{M})$, and MDV3100 $(10 \mu \mathrm{M})$ and cell viability was measured using MTT Assay. Values were normalized to DMSO (control). C. Cell viability results for LNCaP and C4-2 cells at varying concentration of sorafenib, LY294002, and MDV3100 after $24 \mathrm{hrs}$ of treatment. Values were normalized to DMSO (control). Error bars represent standard error (at least 3 repeats with triplicates performed in each experiment). 


\section{Supplementary materials}

\section{Estimation of a population of models using Pareto Optimal Ensemble Techniques}

(POETs). We used multiobjective optimization to estimate an ensemble of prostate models. Although computationally more complex than single-objective formulations, multiobjective optimization can be used to address qualitative conflicts in training data arising from experimental error or cell-line artifacts [33]. In this study we used the Pareto Optimal Ensemble Technique (POETs) to perform the optimization. POETs integrates standard search strategies, e.g., Simulated Annealing (SA) or Local Pattern Search (PS) with a Pareto-rank fitness assignment [81]. The mean squared error, $\eta$, of parameter set $\mathbf{k}$ for training objective $j$ was defined as:

$$
\eta_{j}\left(\mathbf{p}_{k}\right)=\frac{1}{N} \sum_{i}^{N} \frac{\left(\hat{x}_{i, j}-\beta_{j} x\left(\mathbf{p}_{\mathbf{k}}\right)_{i, j}\right)^{2}}{\hat{\sigma}_{i, j}^{2}}
$$

The symbol $\hat{x}_{i, j}$ denotes scaled experimental observations (from training objective $\mathrm{j}$ ) while $x\left(\mathbf{p}_{\mathbf{k}}\right)_{i, j}$ denotes the simulation output (from training objective $\mathbf{j}$ ). The quantity $i$ denotes the sampled time-index or condition, and $N$ denotes the number of time points or conditions for experiment $\mathrm{j}$. The standard deviation, $\hat{\sigma}_{i, j}$, was assumed to be equal to $10 \%$ of the reported observation, if no experimental error was reported. $\beta_{j}$ is a scaling factor which is required when considering experimental data that is accurate only to a multiplicative constant. In this study, the experimental data used for training and validation was typically band intensity from immunoblots, where intensity was estimated using the ImageJ software package [1]. The scaling factor used was chosen to minimize the normalized squared error [5]:

$$
\beta_{j}=\frac{\sum_{i}\left(\hat{x}_{i, j} x_{i, j} / \hat{\sigma}_{i, j}^{2}\right)}{\sum_{i}\left(x_{i, j} / \hat{\sigma}_{i, j}\right)^{2}}
$$


By using the scaling factor, the concentration units on simulation results were arbitrary, which was consistent with the arbitrary units on the experimental training data. All simulation data was scaled by the corresponding $\beta_{j}$.

We computed the Pareto rank of parameter set $\mathbf{k}_{i+1}$ by comparing the simulation error at iteration $i+1$ against the simulation archive, denoted as $\mathbf{K}_{i}$. We used the Fonseca and Fleming ranking scheme [23] to estimate the rank of the parameter set $\mathbf{k}_{i+1}$. Parameter sets with increasing rank are progressively further away from the optimal trade-off surface. The parameter set $\mathbf{k}_{i+1}$ was accepted or rejected by the SA with probability $\mathcal{P}\left(\mathbf{k}_{i+1}\right)$ :

$$
\mathcal{P}\left(\mathbf{k}_{i+1}\right) \equiv \exp \left\{-\operatorname{rank}\left(\mathbf{k}_{i+1} \mid \mathbf{K}_{i}\right) / T\right\}
$$

where $T$ is the computational annealing temperature. The Pareto rank for $\mathbf{k}_{i+1}$ is denoted by $\operatorname{rank}\left(\mathbf{k}_{i+1} \mid \mathbf{K}_{i}\right)$. The annealing temperature was adjusted according to the schedule $T_{k}=\beta^{k} T_{0}$ where $\beta$ was defined as $\beta=\left(\frac{T_{f}}{T_{o}}\right)^{1 / 10}$. The initial temperature was given by $T_{0}=n / \log (2)$, with $n=4$ and the final temperature $T_{f}=0.1$ used in this study. The epoch-counter $k$ was incremented after the addition of 50 members to the ensemble. As the ensemble grew, the likelihood of accepting a high rank set decreased. Parameter sets were generated by applying a random perturbation in log space:

$$
\log \mathbf{k}_{i+1}=\log \mathbf{k}_{i}+\mathcal{N}(0, \nu)
$$

where $\mathcal{N}(0, \nu)$ is a normally distributed random number with zero mean and variance $\nu$, set as 0.1 in this model. The perturbation was applied in log space to account for large variation in parameter scales and to ensure positive parameter values. We used a local pattern search every $q$ steps, in our case 20 , to minimize error for a single randomly selected objective. The local pattern-search algorithm used has been described previously [24]. 
Translation and Transcription Template We utilized the following template for the transcription of genes in the network without a transcription factor:

$$
\begin{gathered}
(1) \mathrm{g}_{P S A}+\mathrm{RNAP} \underset{k_{2}}{\stackrel{k_{1}}{\rightleftharpoons}} \mathrm{g}_{P S A-} \mathrm{RNAP} \\
(2) \mathrm{g}_{P S A} \mathrm{RNAP} \stackrel{k_{3}}{\rightarrow} \mathrm{g}_{P S A}+\mathrm{RNAP}+\mathrm{mRNA}_{P S A}
\end{gathered}
$$

and with a transcription factor:

$$
\begin{gathered}
(3) \mathrm{g}_{P S A}+\left(\mathrm{AR}_{p-} \mathrm{DHT}\right)_{2} \underset{k_{5}}{\stackrel{k_{4}}{\rightleftharpoons}} \mathrm{g}_{P S A-}\left(\mathrm{AR}_{p-} \mathrm{DHT}\right)_{2} \\
(4) \mathrm{g}_{P S A-}\left(\mathrm{AR}_{p-} \mathrm{DHT}\right)_{2}+\mathrm{RNAP} \underset{k_{7}}{\stackrel{k_{6}}{\rightleftharpoons}} \mathrm{g}_{P S A-}\left(\mathrm{AR}_{p-} \mathrm{DHT}\right)_{2} \text { RNAP } \\
(5) \mathrm{g}_{P S A-}\left(\mathrm{AR}_{p-} \mathrm{DHT}\right)_{2} \mathrm{RNAP} \stackrel{k_{8}}{\rightarrow} \mathrm{g}_{P S A}+\left(\mathrm{AR}_{p-} \mathrm{DHT}\right)_{2}+\mathrm{RNAP}+\mathrm{mRNA}_{P S A}
\end{gathered}
$$

RNAP denotes RNA polymerase. Next translation was modeled by the following, where Ribo denotes ribosome:

(6) $\mathrm{mRNA}_{P S A}+$ elF4E $\underset{k_{10}}{\stackrel{k_{9}}{\rightleftharpoons}} \mathrm{mRNA}_{P S A}$ elF4E

(7) mRNA $_{P S A}$ elF4E + Ribo40S $\underset{k_{12}}{\stackrel{k_{11}}{\rightleftharpoons}}$ mRNA $_{P S A}$ elF4E_Ribo40S

(8) mRNA $_{P S A}$ elF4E_Ribo40S + Ribo60S $\underset{k_{14}}{\stackrel{k_{13}}{\rightleftharpoons}}$ mRNA $_{P S A}$-elF4E_Ribo40S_Ribo60S

(9) mRNA $_{P S A \_}$elF4E_Ribo40S_Ribo60S $\stackrel{k_{15}}{\rightarrow}$ mRNA $_{P S A}$ Ribo40S_Ribo60S + elF4E

$(10)$ mRNA $_{P S A}$-Ribo40S_Ribo60S $\stackrel{k_{16}}{\rightarrow}$ mRNA $_{P S A}$ _Ribo40S_Ribo60S_Elong

(11) mRNA $_{P S A}$ RRibo40S_Ribo60S_Elong $\stackrel{k_{17}}{\rightarrow} \mathrm{PSA}+\mathrm{mRNA}_{P S A}+\mathrm{Ribo40S}+$ Ribo60S 
Table T1: Objective function list along with species measured, stimulus, cell-type, steady state (SS) vs dynamic (D) and the corresponding literature reference.

\begin{tabular}{|c|c|c|c|c|c|}
\hline O\# & Species & Cell Type & Stimulus & SS or D & Source \\
\hline O1 & PSA & C33/C81 & 0 & SS & {$[48]$} \\
\hline $\mathrm{O} 2$ & PSA & C33 & DHT & $\mathrm{D}$ & [48] \\
\hline О3 & PSA & $\mathrm{C} 81$ & DHT & $\mathrm{D}$ & {$[48]$} \\
\hline $\mathrm{O} 4$ & ERK-p & C33 & DHT & $\mathrm{D}$ & {$[48]$} \\
\hline O5 & ERK-p & C81 & DHT & D & [48] \\
\hline 06 & PSA & C33 & HER2 Knockdown & ss & [48] \\
\hline $\mathrm{O} 7$ & PSA & C81 & HER2 Knockdown & ss & [48] \\
\hline O8 & PSA & C33 & MEK Up & SS & [48] \\
\hline ०9 & PSA & C81 & MEK Down & SS & {$[48]$} \\
\hline O10 & PSA & C33 & HER2 Up & SS & [48] \\
\hline O11 & ERK-p & С33 & HER2 Up & SS & [48] \\
\hline 012 & $A R$ & C33/C51/C81 & 0 & SS & [53] \\
\hline 013 & PAcP mRNA & C33 & DHT & $\mathrm{D}$ & [53] \\
\hline O14 & PAcP mRNA & C51 & DHT & $\mathrm{D}$ & [53] \\
\hline 015 & PAcP mRNA & C81 & DHT & $\mathrm{D}$ & {$[53]$} \\
\hline 016 & HER2-p & С33/C51/C81 & 0 & ss & [98] \\
\hline O17 & Cyclin D & C33/C81 & 0 & SS & CITE \\
\hline 018 & Cyclin D & C33 & EGF & D & {$[66]$} \\
\hline O19 & Cyclin D mRNA & C33 & EGF & D & {$[66]$} \\
\hline $\mathrm{O} 20$ & AKT-p & C51/LNCaP-Rf & 0 & SS & [62] \\
\hline $\mathrm{O} 21$ & p27Kip1 & C51/LNCaP-Rf & 0 & SS & [62] \\
\hline O22 & p21Cip1 & C51/LNCaP-Rf & 0 & SS & [62] \\
\hline $\mathrm{O} 23$ & $R b-p$ & C33 & DHT & $\mathrm{D}$ & [94] \\
\hline $\mathrm{O} 24$ & p70-p & C33 & DHT & D & [94] \\
\hline $\mathrm{O} 25$ & p21Cip1 & C33 & DHT & $\mathrm{D}$ & [46] \\
\hline $\mathrm{O} 26$ & p27Kip1 & С33 & DHT & $\mathrm{D}$ & {$[46]$} \\
\hline $\mathrm{O} 27$ & PSA mRNA & С33 & Cyclin E Up + DHT & D & [95] \\
\hline $\mathrm{O} 28$ & AR mRNA & C33 & Cyclin E Up + DHT & D & [95] \\
\hline O29 & PSA mRNA & C33 & HER2 Up & SS & {$[96]$} \\
\hline O30 & AKT-p & C33/C51 & 0 & SS & [51] \\
\hline O31 & AR & C51 & DHT & D & [51] \\
\hline
\end{tabular}


bioRxiv preprint doi: https://doi.org/10.1101/058552; this version posted June 13, 2016. The copyright holder for this preprint (which was not certified by peer review) is the author/funder, who has granted bioRxiv a license to display the preprint in perpetuity. It is made available under aCC-BY 4.0 International license.

974

$\begin{array}{llllll}\text { O32 } & \text { AR } & \text { C33 } & \text { DHT } & \text { D } & {[12]} \\ \text { O33 } & \text { Cyclin D1b mRNA } & \text { C33 } & \text { Sam68 Knockdown } & \text { SS } & {[65]} \\ \text { O34 } & \text { AR mRNA } & \text { C33 } & \text { E2F Up } & \text { SS } & {[18]} \\ \text { O35 } & \text { AR } & \text { C33 } & \text { E2F Up } & \text { SS } & {[18]} \\ \text { O36 } & \text { AR Cyclin E } & \text { C33 } & \text { E2F Up } & \text { SS } & {[18]} \\ \text { O37 } & \text { PSA } & \text { C33 } & \text { E2F Up } & \text { SS } & {[18]} \\ \text { O38 } & \text { cPAcP } & \text { C33 } & \text { DHT } & \text { D } & {[60]} \\ \text { O39 } & \text { Cyclin D } & \text { C33 } & \text { DHT } & \text { D } & {[94]} \\ \text { O40 } & \text { 4EBP1-p } & \text { C33 } & \text { DHT } & \text { D } & {[94]} \\ \text { O41* } & \text { PAcP mRNA } & \text { C33/C51/C81 } & 0 & \text { SS } & {[53]} \\ \text { O42 }^{*} & \text { p16INK4 } & \text { C51/C81 } & 0 & \text { SS } & {[62]} \\ \text { O43* }^{*} & \text { cPAcP } & \text { C33/C51/C81 } & 0 & \text { SS } & {[54]}\end{array}$


Table T2: Blind Prediction list along with species measured, stimulus, cell-type, steady state (SS) vs dynamic (D) and the corresponding literature reference.

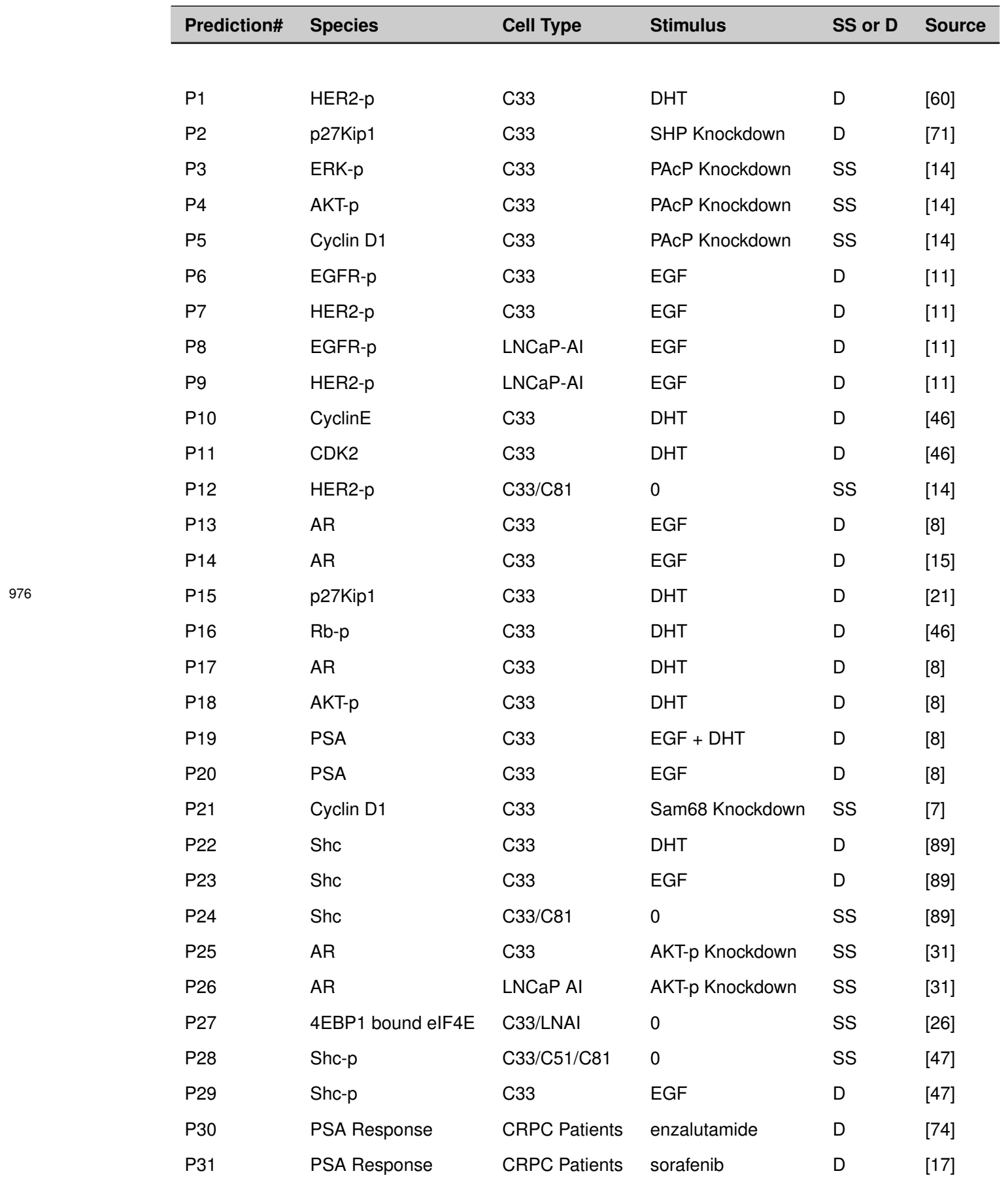


bioRxiv preprint doi: https://doi.org/10.1101/058552; this version posted June 13, 2016. The copyright holder for this preprint (which was not certified by peer review) is the author/funder, who has granted bioRxiv a license to display the preprint in perpetuity. It is made available under aCC-BY 4.0 International license.

$\begin{array}{llllll}\text { P32 } & \text { PSA Response } & \text { CRPC Patients } & \text { lapatinib } & \text { D } & \text { [93] } \\ \text { P33 } & \text { PSA Response } & \text { ADPC Patients } & \text { lapatinib } & \text { D } & \text { [55] }\end{array}$




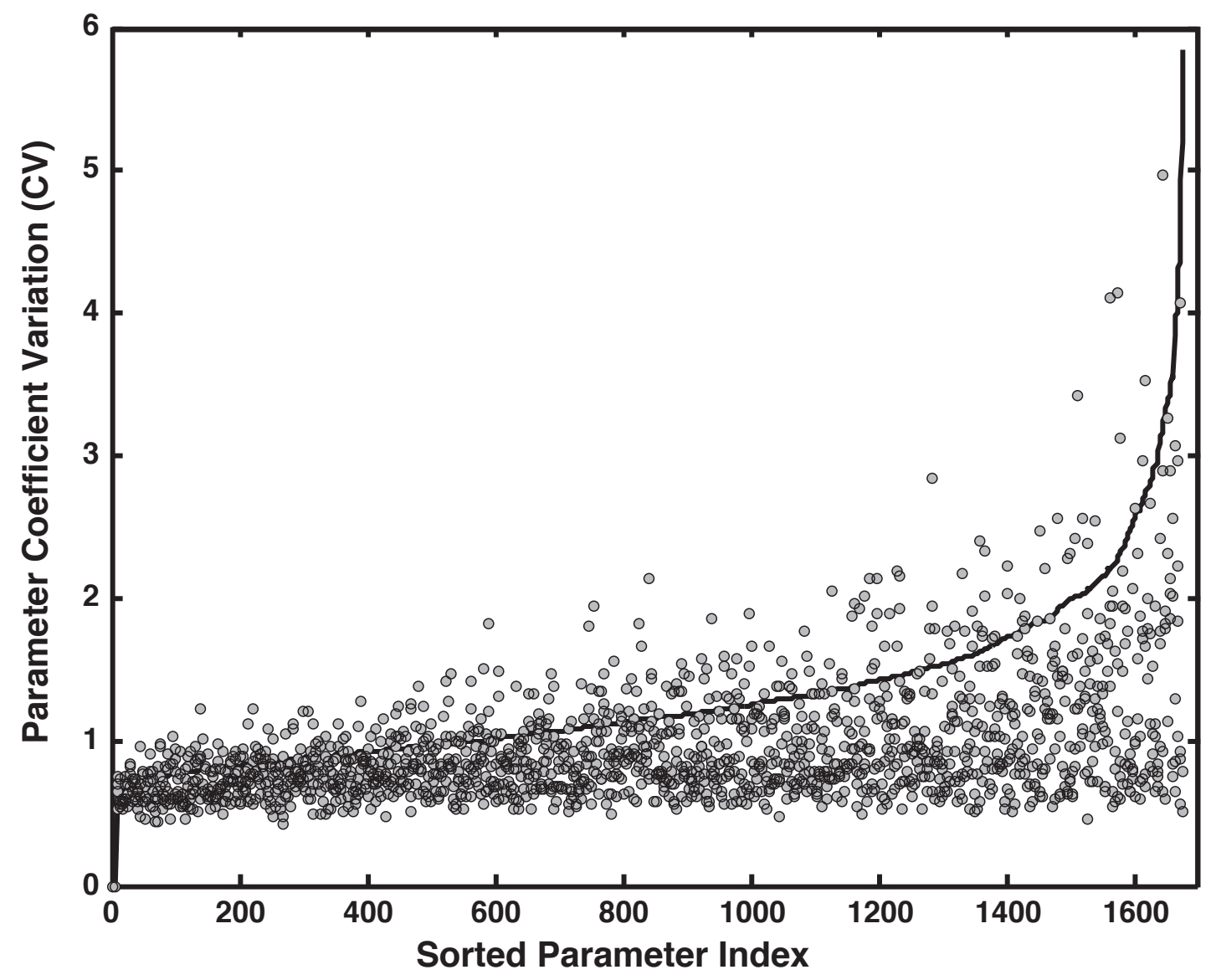

Fig. S1: Coefficient of variation (CV) of model parameters estimated using POETs. The solid line denotes the mean CV calculated over the entire ensemble $(N=5000)$. The points denote the mean CV of the 500 ensemble members used for sensitivity and robustness calculations. Over the ensemble, the coefficient of variation $(\mathrm{CV})$ of the kinetic parameters spanned $0.59-5.8$, with $33 \%$ of the parameters having a CV of less than one. 
A.

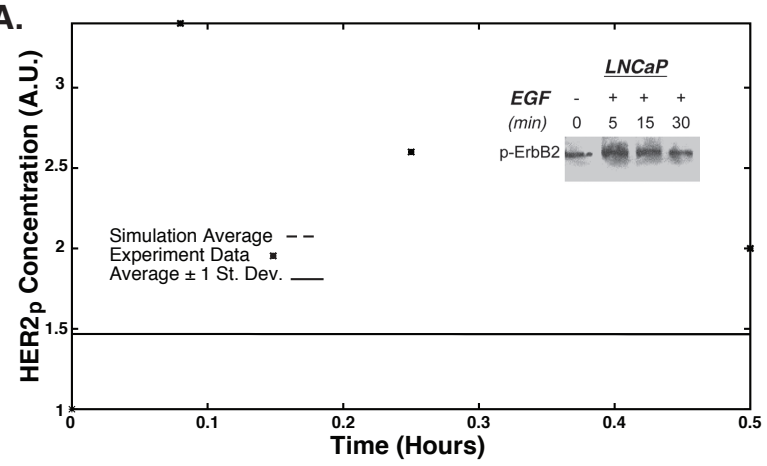

C.

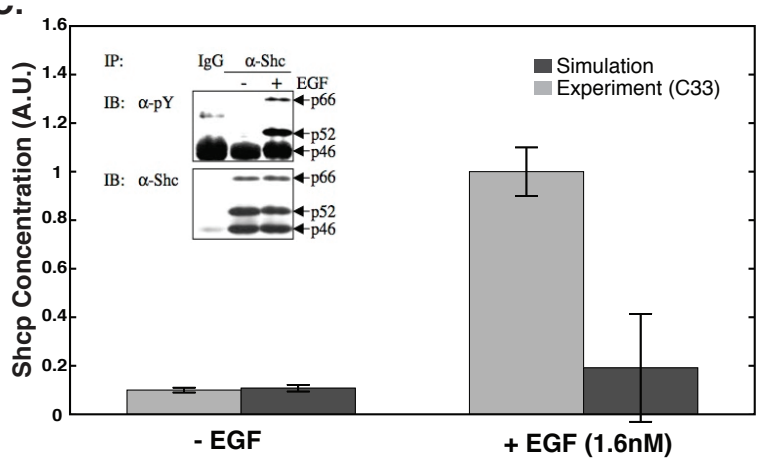

B.

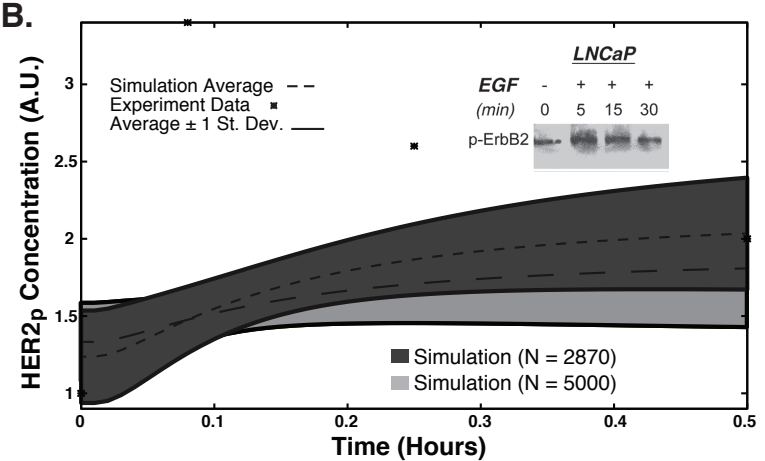

D.

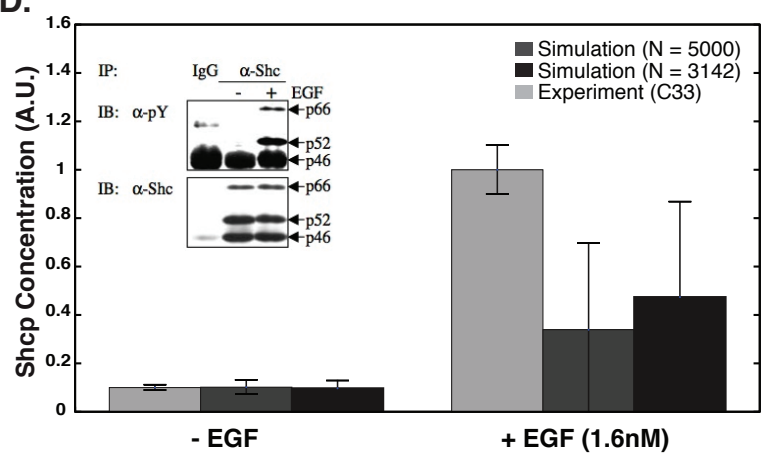

Fig. S2: Blind model predictions for the ensemble with the original and updated model (EGFR and HER2 heterodimer). A,B. Time course data for HER2 phosphorylation due to a stimulus of $1.6 \mathrm{nM}$ EGF (LNCaP C33, P7) for the old and new model, respectively. Dark grey shows only parameters improved by the updated model $(\mathrm{N}=2870)$ while light grey show all parameter sets $(\mathrm{N}=5000)$. C,D. Shc phosphorylation levels at $16 \mathrm{hrs}$ in the presence and absence of $1.6 \mathrm{nM} \mathrm{EGF} \mathrm{(LNCaP} \mathrm{C33,} \mathrm{P29)} \mathrm{for} \mathrm{the} \mathrm{old} \mathrm{and} \mathrm{new} \mathrm{model,}$ respectively. Light grey denotes experimental data, mid grey denotes simulation results for all parameters $(\mathrm{N}=5000)$, and black denotes only parameters improved by the updated model $(\mathrm{N}=3142)$. Error bars denote plus and minus one standard deviation from the mean. 
A.

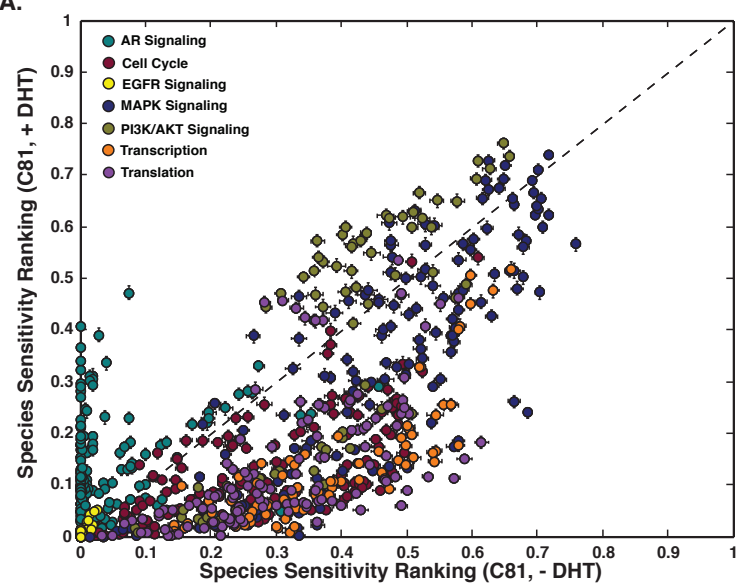

c.

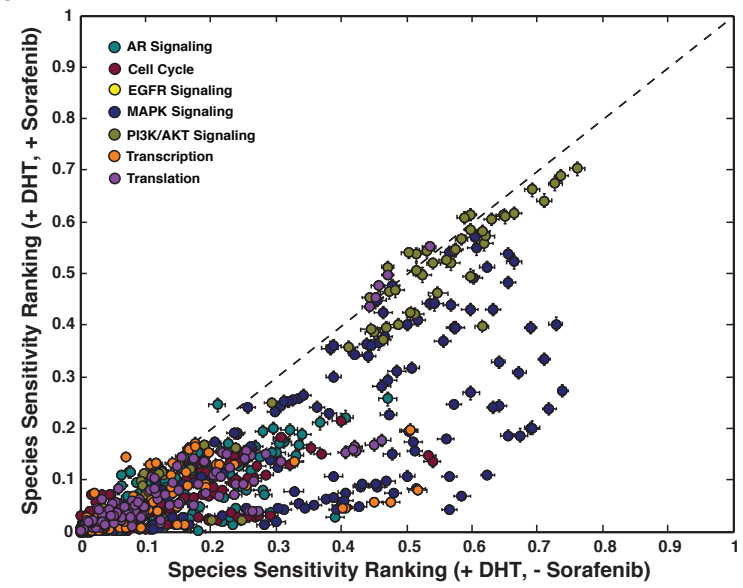

B.

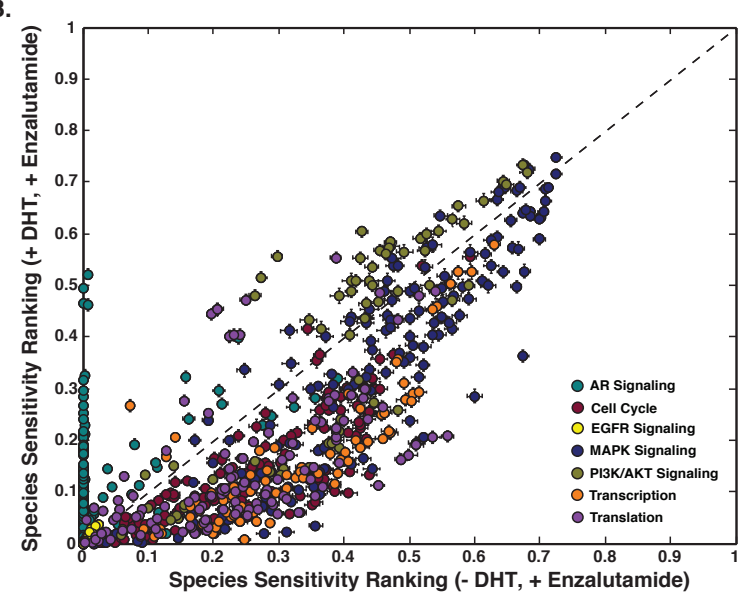

D.

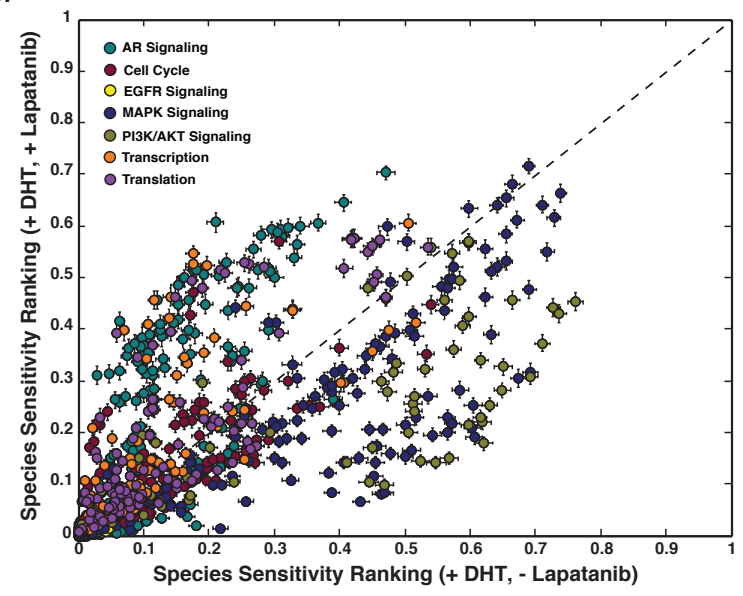

Fig. S3: Sensitivity analysis of a population of prostate models $(N=500)$. Species with a low sensitivity are considered robust, while species with a high sensitivity ranking are considered fragile. A Sensitivity ranking of network species in CR cells in the absence and presence of DHT. B. Sensitivity ranking of network species in CR cells in the presence of enzalutamide in the presence and absence of a DHT stimulus. C., D. Sensitivity ranking of network species in CR cells in the presence and absence of sorafenib and lapatinib, respectively, with a DHT stimulus. Error bars denote standard error with $\mathrm{N}=500$. 

aCC-BY 4.0 International license.

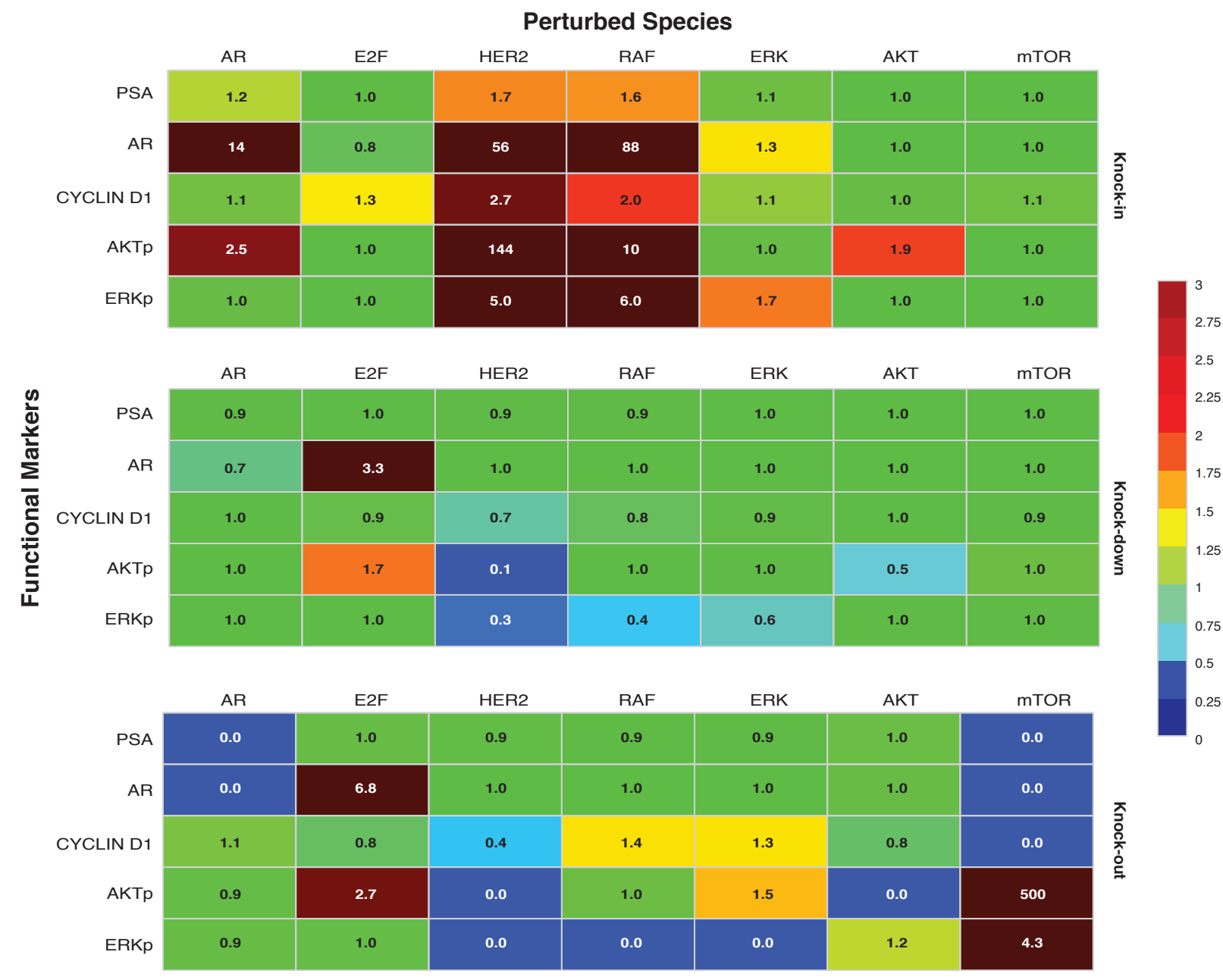

Fig. S4: Robustness analysis of protein markers. Expression level of key proteins was altered by a factor of $2,0.1$, or 0 (knock-in, knock-down, or knock-out) and robustness coefficients were calculated for five key protein markers. Simulations shown were from CR cells, with indicated perturbation. Mean of 500 ensemble members is shown. 


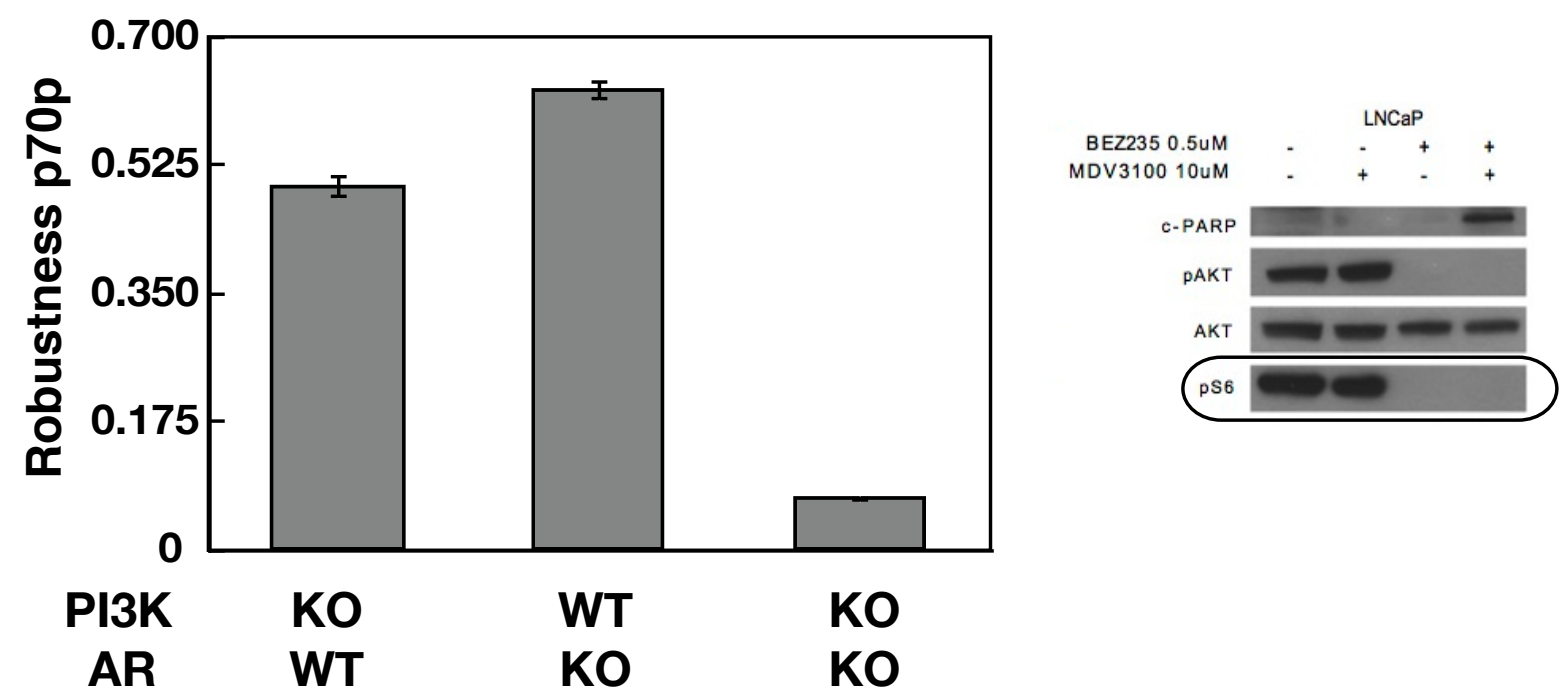

Fig. S5: Dual knock-out of AR and PI3K leads to decreased expression of activated p70. A., B, C. Robustness coefficient of activated p70 (S6) in the PI3K knock-out, AR knock-out, and dual knock-out cases, respectively. The control was the basil CR LNCaP wild type case. Error bars denote plus and minus one standard error from the mean with $\mathrm{N}=500$. Experimental data is from Carver, et al [10]. 